\title{
Propagation Problems With Space Radio Communications ${ }^{1}$
}

\author{
Karl Rawer \\ Contribution from Ionosphären Institut Breisach im FTZ der Deutschen Bundespost
}

(Received November 6, 1961)

\begin{abstract}
Ionospheric and tropospheric refraction and absorption influence earth-space propagation. The relative importance of the ionospheric influence is considerably larger than in terrestrial propagation. Apart from the effects of this latter known from experience, some new phenomena have been observed, viz, special cases of antipode reception, field-strength scintillations and blackouts. Specific phase effects have been observed: the Doppler-effect is due to the satellites quick movement, the Faraday effect is caused by the presence of double refraction in the ionosphere. Both effects present some difficulties for most applications. The most important tropospheric effects are molecular absorption and the corresponding statistical noise.
\end{abstract}

\section{Introduction}

The radio communication problem between transmitters in space and the earth is older than are artificial earth satellites; it has been under discussion since the beginning of work in radio astronomy. So far we have some experience with it. On the other side the radio-astronomical experience does not cover some typical features which are important for space radio communications. From this point of view our problem is a new one, and experience with it is yet very limited. Also we should look forward to an entirely new class of propagation problems, viz, those arising with communications between two points somewhere in space. But for the time being this is not yet a practical problem. The following discussion is therefore mainly limited to earth-space communications.

It is also limited to the most interesting frequency range, i.e., that of the "radio astronomical window." This range is rather large; it goes from about 10 $\mathrm{Mc} / \mathrm{s}$ through $100 \mathrm{Gc} / \mathrm{s}$. Propagation influences are quite important at both boundaries so that the easiest range for communication may be 1 through $10 \mathrm{Gc} / \mathrm{s}$. Seen as a propagation problem the boundary ranges are of particular interest; therefore the following discussion will be nearly entirely devoted to these, mainly to the lower one. The "radio-astronomical window" is not the only one by which electromagnetic waves can penetrate to and from space. In addition to the "optical window" there is a third one in the ELF range. The latter two will not be discussed here.

Refraction and attenuation are the most prominent propagation effects. For practical orientation purposes we propose to summarize the result of the combined influences by the "extra-terrestrial antenna pattern." With this notion we intend to describe the effective diagram after penetration of

\footnotetext{
1 The author has recently reported on the same subject in a condensed form at
} the URSI Symposium on Space Communications held at Paris, September 1961 the earth's atmosphere. By definition this is a combination of the true antenna pattern with the result of propagation influences ocurring somewhere in the atmosphere. While this is a practical definition we need another notion in order to select the propagation influences only. Therefore we define a "standard extra-terrestrial antenna pattern"; this is the antenna pattern of an isotropic antenna after penetration of the waves through the atmosphere,

It is well known from radio astronomy that the lower frequency limit of the radio-astronomical window is given by ionospheric refraction influences while the upper one is due to tropospheric attenuation. In the following we shall therefore first discuss the ionospheric influences and then the tropospheric ones.

\section{Regular Ionospheric Refraction}

Refraction in the ionosphere is due to the secondary radiation of the free electrons in the plasma, more precisely to oscillations of these electrons which are excited by the electromagnetic waves. Compared with optical or microwave refraction the only difference should be that the electrons are not bound and resonance effects should not occur. This is essentially true for frequencies above $100 \mathrm{Mc} / \mathrm{s}$, where Sellmeir's dispersion formula is quite satisfactory:

$$
\begin{gathered}
n^{2}=1-f_{N}^{2} / f^{2}, \text { with } \\
f_{N}=\frac{1}{2 \pi} \sqrt{\frac{q^{2} N}{m \epsilon_{0}}}=\text { plasma frequency }
\end{gathered}
$$

( $n$ index of refraction, $f$ frequency, $q$ charge and $m$ mass of the electron, $N$ electron density, $\epsilon_{0}$ dielectric constant of free space). It follows that the ionosphere is optically thinner than free space.

If the frequency is high compared to the plasma frequency, as it is in most applications which we shall consider, eq (1) can be approximated by 


$$
n-1=-\frac{1}{2} f_{N}^{2} / f^{2}=-\frac{1}{2 \epsilon_{0}} \frac{q^{2}}{m} \frac{1}{(2 \pi f)^{2}} N .
$$

The refraction effect is proportional to the local plasma density $N$.

For lower frequencies the influence of the magnetic field of the earth cannot be completely neglected. We have the Lassen and Appleton dispersion formula which is complicated by the vector character of the magnetic field which causes anisotropy and double refraction. This latter phenomenon is important for the Faraday effect (see sec. 4.3). It should be noted that the effect of the magnetic field on refraction depends mainly on the ratio of the frequency to the resonance frequency of free electrons in the magnetic field, the so-called gyrofrequency, $f_{H}$. This is proportional to the local magnetic induction $B$; so it decreases with the distance from the earth as $\left(r / r_{T}\right)^{-3}$, the value at the surface $\left(r=r_{T}\right)$ being about $1.3 \mathrm{Mc} / \mathrm{s}$ at temperate latitudes. The effects of the magnetic field decrease rather rapidly with increasing frequency, about as $1 / f^{2}$, but it depends on the particular effect whether the Lassen-Appleton formula can be replaced by the much simpler Sellmeier formula. It is impossible to indicate precise frequency limits for the magnetic influence. While the curvature of the ray does not seriously depend on it at frequencies above $20 \mathrm{Mc} / \mathrm{s}$, phase effects are more sensitive; in particular, the Faraday effect which is a direct consequence of double refraction can be important on much higher frequencies up to $1 \mathrm{Gc} / \mathrm{s}$.

1.1. Equation (1) shows that the refractive influence is decreasing with increasing frequency. The most important effects therefore are found at lower frequencies. The maximum value of the plasma frequency in a stratified ionosphere is usually called the critical frequency, $f_{c}$. This notion gives a simple classification: at frequencies $f<f_{c}$ even at vertical incidence the ionosphere cannot be penetrated. $f_{c}$ therefore is the precise lower limit of the window range. On frequencies higher than $f_{c}$ penetration is possible for steep rays first (fig. 1). With increasing frequency the penetration cone becomes larger and larger. Finally we come to another frequency limit which is not so commonly used. We define as $f_{d}$ the limiting frequency for which the ray, which is horizontal at the earth, just penetrates the ionosphere. Such a limit exists only as a consequence of the validity of the curved layer refraction law (fig. 2)

$$
n r \sin \alpha=\mathrm{const}=r_{0} \sin \alpha_{0}
$$

( $\alpha$ the angle between $r$ and the wave normal) and the fact that the ionospheric layers are always found above a certain altitude. Therefore the angle $\alpha$ has a well defined upper limit, since it cannot approach $90^{\circ}$ as it normally does in the case of tropospheric propagation. Of course a refraction effect exists also on frequencies above $f_{d}$. However, there can no longer be reflection of rays by the ionosphere so that every ray coming from a transmitter on the earth penetrates the ionosphere.

The double refraction has the effect that slightly higher characteristic frequencies are valid for extraor- dinary than for ordinary rays, formula (1) being a good approximation for the latter one.

1.2. The highest electron density occurs nearly always in the F2-layer of the ionosphere so that normally $f_{c}$ is identical with $f_{0} F_{2}$, the corresponding height being of the order of $300 \mathrm{~km}$. These parameters or equivalents are observed at ionospheric stations. The variations of this critical frequency are very large; values between about 1 and 20 $\mathrm{Mc} / \mathrm{s}$ are found, variable with hour, season and site. Generally the lowest values are found at higher latitudes, but very low values can also occur at night in equatorial regions. The highest values are found during the day in two belts north and south of the magnetic equator. On rare occasions, in particular when the critical frequency of the F2 layer is very low, the effective critical frequency of the ionosphere can be found in the $F 1$ layer, at about $160 \mathrm{~km}$, or in the Es layer, at about $100 \mathrm{~km}$.

As to $f_{d}$, it depends on both the critical frequency and the height of the layer. As lower layers allow for higher values of $\alpha_{0}, \tilde{f}_{d}$ is more often determined by the Es-layer than is $f_{c}$. Nevertheless in most cases $f_{d}$ is given by the parameters of the $F 2$ layer. The height variations of this layer are quite appreciable; values between 250 and $500 \mathrm{~km}$ can occur, the highest values being found in the equatorial zone. $f_{d}$ also is largely variable; while the lowest (nighttime) values are of the order of 5 $\mathrm{Mc} / \mathrm{s}$, the highest values due to $F 2$ go up to 55 $\mathrm{Mc} / \mathrm{s}$. Even higher values can be obtained occasionally with $E s$.

No direct routine determination of $f_{d}$ is actually made at ionospheric stations but the parameter MUF(3000)F2 has a certain relation with it. For future work on ionospheric refraction of penetrating rays one should have a practical way to determine $f_{d}$ from the routine parameters reduced from vertical soundings.

1.3. When the frequency is between $f_{c}$ and $f_{d}$, ray geometry is rather complicated. Roughly speaking there is a cone of penetrating rays which is limited by the critical reflection condition at the level of maximum electron density $(\operatorname{suffix} c)$.

$$
n_{c} r_{c}=r_{0} \sin \alpha_{0}=r_{T} \sin \alpha_{T} .
$$

The value of $\alpha_{T}$ so found defines a cone of rays at the transmitter but the corresponding rays outside the ionosphere have another convergency point. The limiting ray given by (3) cannot penetrate the layer; if the ionosphere were homogeneous this ray should follow the curvature of the layer approaching asymptotically the height $r_{c}$. So it is strongly deviated by refraction. A similar statement is true for neighboring rays. Those which are less steep are reflected at large distance; they are called Pedersen rays. Those which are steeper penetrate the layer but with an important lateral deviation due to refraction (fig. 3).

In principle there is no geometrical limit to these deviated rays. At frequencies above $f_{d}$ a geometricoptical radio horizon is well defined by the refraction of the ray with horizontal start $\left(\alpha_{T}=90^{\circ}\right)$ [Carru 

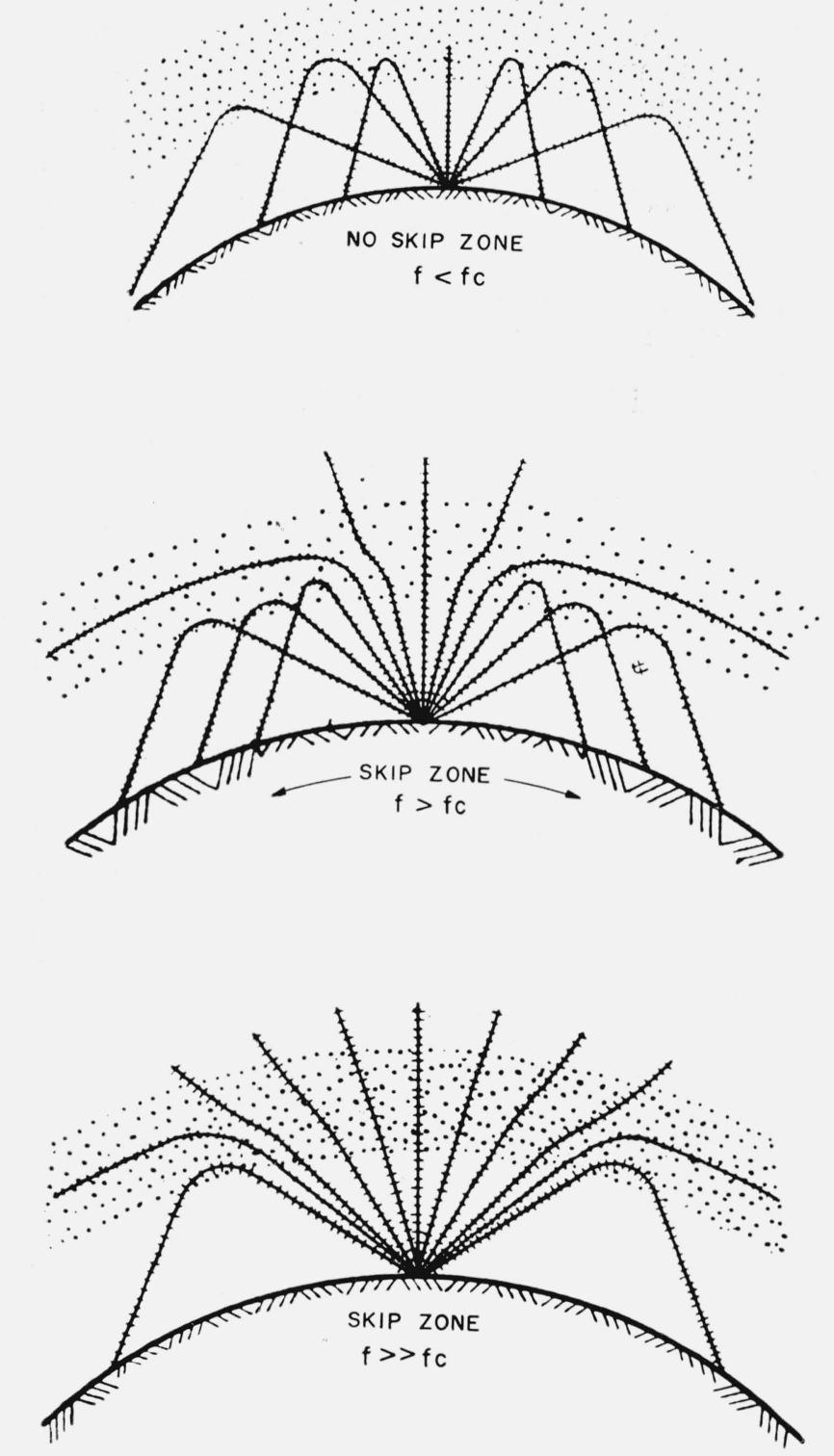

Figure 1. Refraction for different frequencies between $f_{c}$ and $f_{d}$.

et al., 1960b]. However, with $f$ between $f_{c}$ and $f_{a}$ rays can even go across the optical horizon in spite of the limitation of the cone at the transmitter. A practical limitation is given by the photometric decrement, i.e., the dilution of energy which is a consequence of the large spread of the rays due to refractional deviation [Rawer, 1960]. All the largely deviated rays originate from a small bundle near the critical ray. The importance of this refraction effect depends on the layer thickness; only with thick layers large refractional deviation is obtained. The effects are therefore negligible for $E$ s-layers, but rather large for equatorial $F 2$-layers. In the case of a thick homogeneous F2-layer the ray can be deviated well above the optical horizon if we allow for an additional photometric decrement of 10 to $20 \mathrm{db}$ [Rawer, 1960].

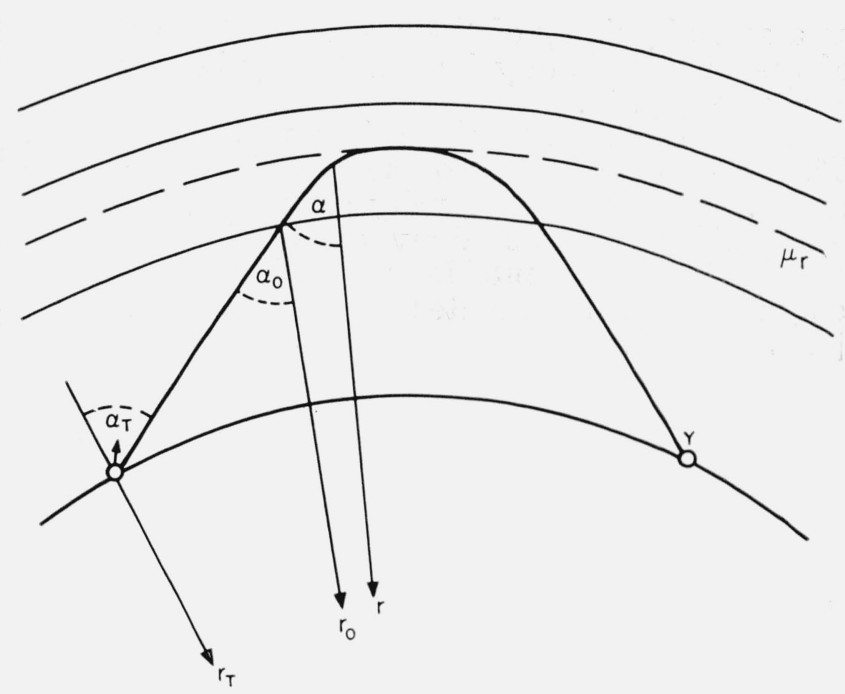

FigURE 2. Ray geometry for a curved layer (replace $\mu_{r}$ by $n_{r}$.

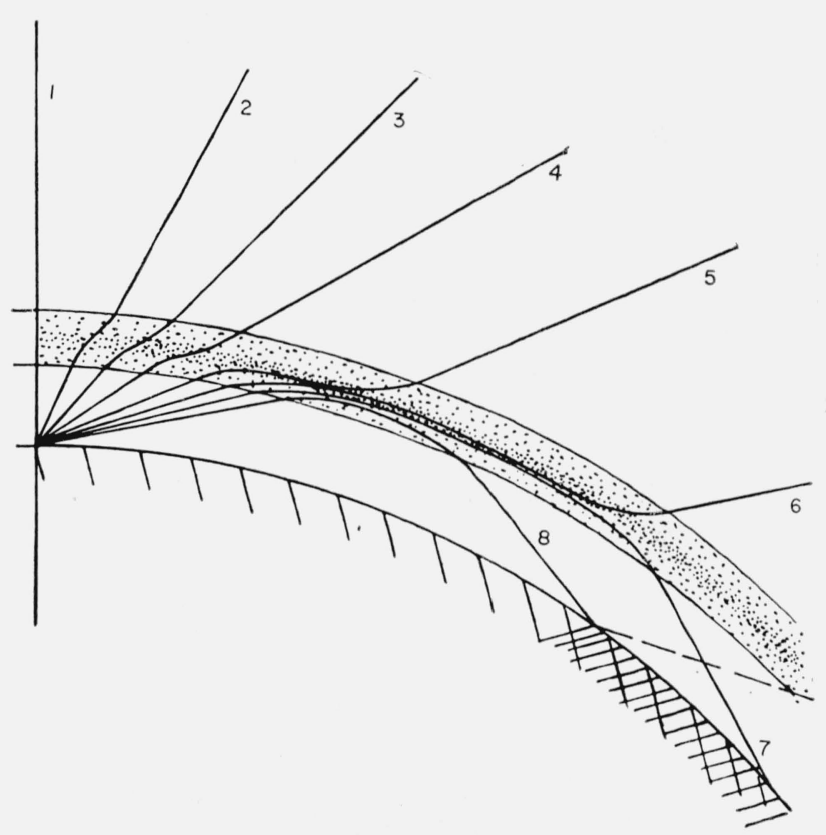

FIgURE 3. Refracted rays for a transmitter on ground.

1.4. It is instructive to consider the case of a transmitter in space outside the ionosphere (fig. 4). The limitations of $\alpha_{0}$ which determine $f_{d}$ do not exist for rays falling from outside upon the ionosphere. For rays coming from outside no limiting frequency exists at grazing incidence; even UHF frequencies should be reflected by the ionosphere. If the condition $f_{c}<f<f_{d}$ is valid no geometricoptical limit exists for the "illumination range" on the earth, largely deviated rays being able to reach every point at the surface, in principle at least.

Even on frequencies above $f_{d}$ ionospheric refraction should not be negligible in the case of a transmitter outside the ionosphere. In principle the action of a homogeneous curved ionosphere can be described 
as a sort of guiding of the rays so that the shadow of the earth is faintly illuminated by largely deviated rays (fig. 5).

1.5. The real ionosphere is not homogeneous. This puts some limits to the considerations made above. Lack of homogeneity should minimize the effects of largely deviated rays so that the real photometric attenuation outside the limiting cone is probably larger than calculated with geometrical optics [Rawer, 1960].

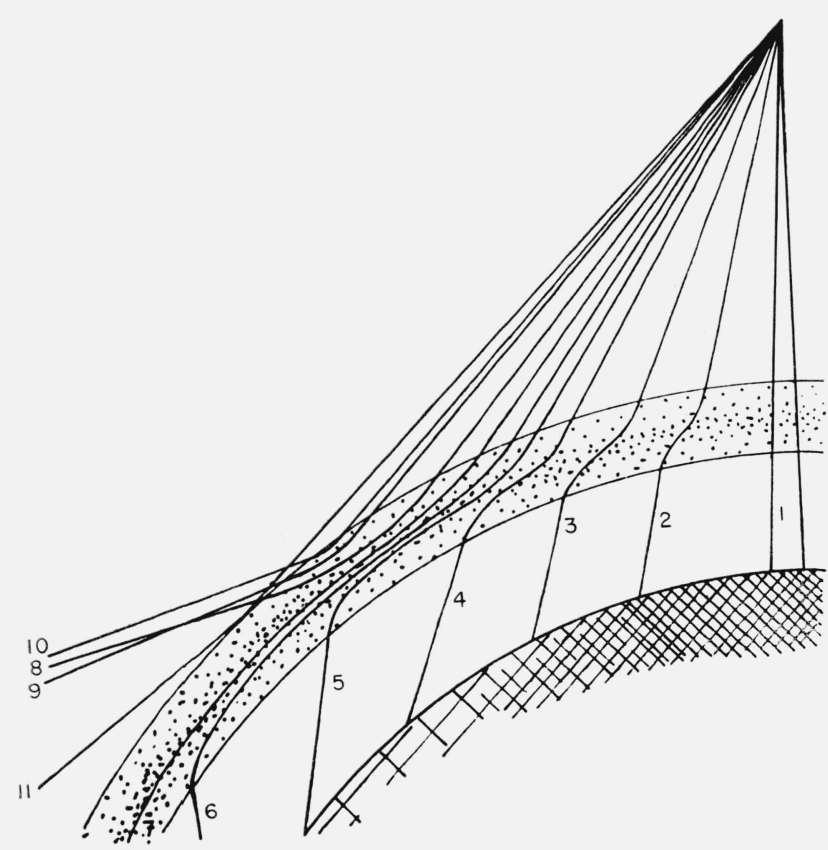

Figure 4. Refracted rays for a transmitter in space.

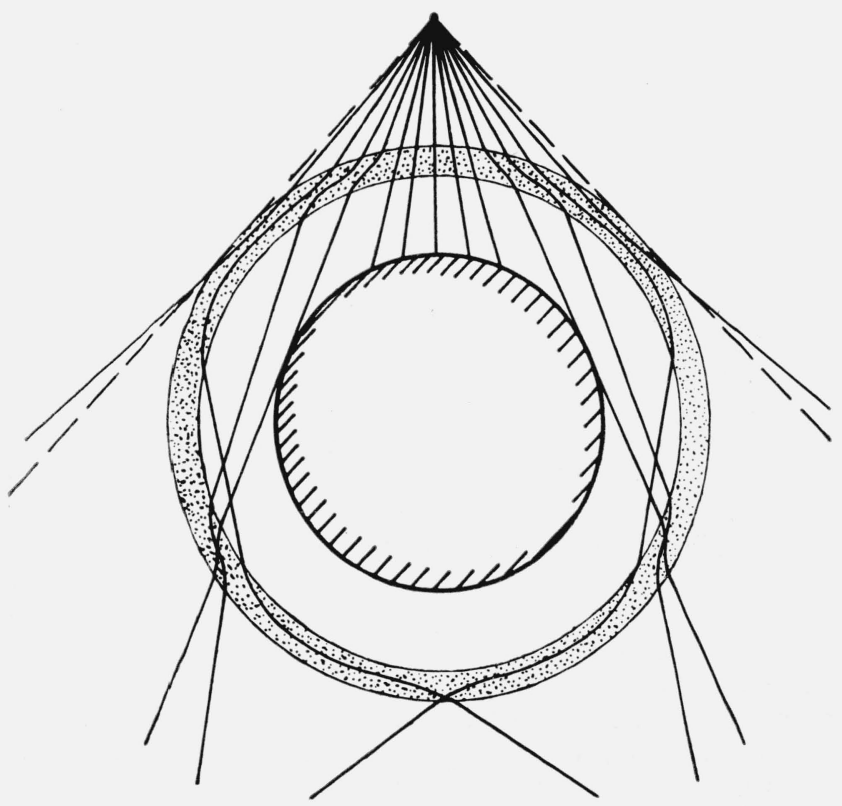

Figure 5. Refracted rays for a transmitter in space, homogeneous ionosphere, $f>f_{d}$.
In the case of a transmitter outside of the ionosphere the most interesting features appear only in the case of an inhomogeneous ionosphere. When a ray propagates in a direction of increasing electron density it is possible that the ionosphere is first penetrated but after reflection from the ground [Bain and Golton, 1960] the same ray at another place can be reflected by the ionosphere (fig. 6). These are rays creeping into the flat region between ground and ionosphere. The situation is quite different when the electron density decreases in the direction of propagation. In that case the ray after ground reflection definitively goes out (fig. 6). Speaking of the transmitter as a light source we obtain a complicated illumination pattern on the earth's surface. We distinguish different zones [Rawer, 1960] according to the following three classes: directly illuminated zones-zones with indirect illumination by ionospheric reflection - shadow zones of the earth or of the ionosphere. A simple practical solution is needed for this particular problem of ionospheric propagation. It should be possible by applying appropriate ionization maps. Also in the case of a transmitter on the earth the inhomogeneity of the ionosphere has important consequences. The overhead "iris" in the ionosphere through which the rays can penetrate is no longer circular, it can have a complicated shape. The reasonings of ray geometry apply in a similar way as explained in sec. 1.3. The standard extraterrestrial diagram is heavily influenced by refraction in the case where $f_{c}<f<f_{d}$. Roughly speaking its shape is determined by the boundaries of the penetration cone. Some smoothing is introduced by deviated rays; therefore the antenna pattern now extends below the horizon; however, with very small intensity. This is different in the case $f>f_{d}$ where the refraction influence on the standard antenna pattern is rather small.

1.6. In the case where the transmitter or the receiver or both are inside the ionosphere some new refraction phenomena can occur. We have seen in

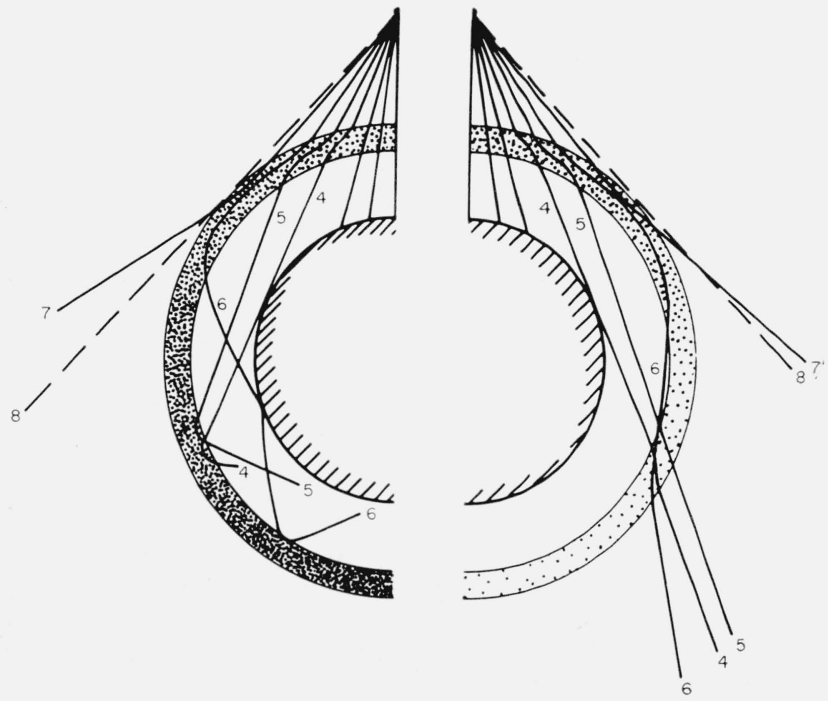

FiguRE 6. Refracted rays for a transmitter in space, inhomogeneous ionosphere. 
sec. 1.1 that the well-known frequency limitation of ionospheric reflection is due to the fact that the ionosphere is at a finite height above the transmitter on the earth. With a transmitter in the refracting layer itself this limitation is no longer valid, and one should expect to obtain ionospheric propagation at higher frequencies than usual. We have conditions similar to the case of (terrestrial) tropospheric reflections. It is shown by figures 3 through 6 that the zone of maximum ionization can be considered as something like a guide or duct; however, this guide is unstable since a small inhomogeneity can cause a ray to go out of the guide. This is the situation at the maximum of ionization, where $n \cdot r$, eq (2), has a minimum. But another stable duct should occur at an altitude where $n \cdot r$ is maximum [Woyk, 1959a and b]. Such a maximum should exist at a height, where the electron density has a minimum, as in the "valley" between $E$ and $F$ region (fig. 7 ).

A similar duct could also occur without a true minimum of electron density at the lower side of a layer because there also occurs a maximum of $n \cdot r$. The physical reason is that rays leaving the lower border of the ionosphere nearly horizontally will come back to this border if the layer is curved. This propagation mode should be easily obtainable between two points in the duct. Occasionally as pointed out by Woyk [1959a and b] in figure 7 it should also appear between a satellite at lower altitude and the earth, namely in the case where an inhomogeneity of the ionosphere somewhere opens a gate from the duct to the earth [Woyk, 1959 a and b; Macrakis, 1960]. A similar propagation mode has formerly been found with back-scatter experiments [Stein et al., 1957].
1.7. Experimental evidence on the different refraction phenomena with satellites is yet very rare. No systematic experimental investigation of the effects of largely deviated ravs (sec. 1.3) has come to the author's knowledge neither comparison between ionospheric echo phenomena and instantaneous ionization maps. But many of the Doppler-observations on 20 and $40 \mathrm{Mc} / \mathrm{s}$ show the presence of ionospheric reflection - either by the appearance of a second frequency or, more often, by an irregular shape of the Doppler curve, sometimes by a reincrease of frequency. An example of a rather irregular Doppler curve is given in figure 8 [Hess and Rawer, 1960]. Observations have been made where the field strength increased again when the satellite was near the horizon; several frequency components appeared in these cases [Dewan, 1959]

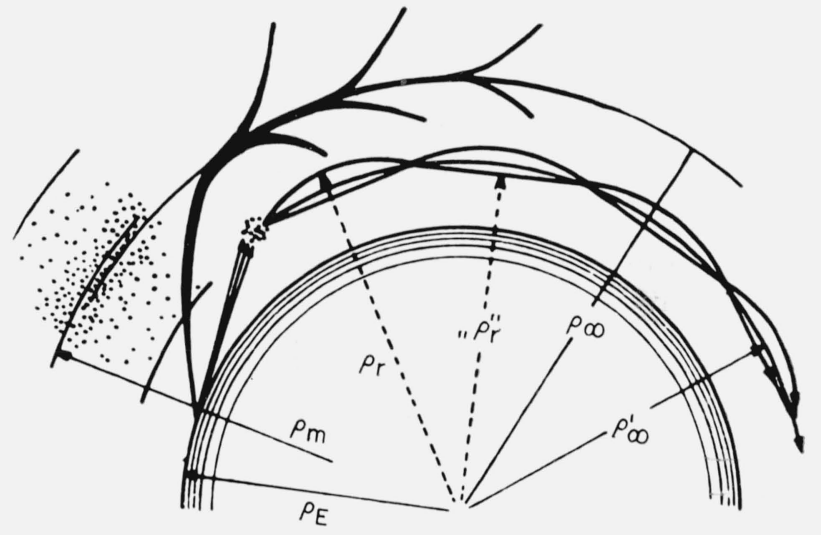

Figure 7. The unstable F2-layer duct and the stable duct in the lower ionosphere [WOYK 1959].

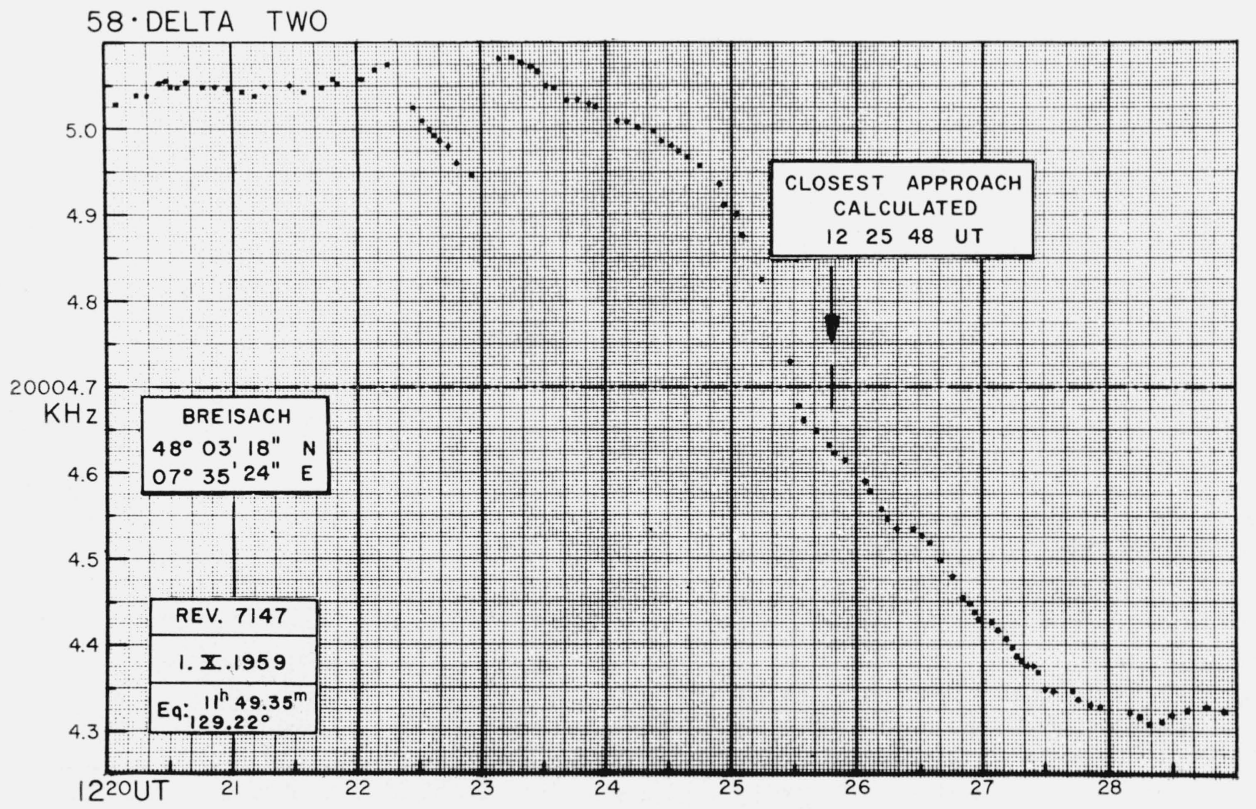

Figure 8. Doppler-curve (1958 Delta II, $20 \mathrm{Mc} / \mathrm{s}$ Breisach) showing strong deformations by ionospheric influences, also a dropout. 
A quite unexpected propagation phenomenon has been reported several times on 20 as well as on 40 $\mathrm{Mc} / \mathrm{s}$. The satellite was intercepted between two regular passings when it was in the antipode range. Most of these observations are reported from satellites at rather low altitude [Hess, 1958 and 1960]. It is also reported that in these cases the frequency was rather constant [Garriot and Villard, 1958]. Interferometric observation on $40 \mathrm{Mc} / \mathrm{s}$ showed the same features as obtained with a point source [Wells, 1958]. It is felt that these observations fit well with the ionospheric duct theory as explained before in sec. 1.6, figure 7 [Woyk, $1959 \mathrm{a}$ and b]. It is also possible that a ray penetrates the ionosphere near the antipode and is then reflected between earth and ionosphere (fig. 6). But this latter explanation is limited to lower frequencies than is the duct theory.

\section{Irregular Ionospheric Refraction}

2.1. Radio-astronomical observations have shown that under certain conditions irregular refraction effects play a very important role. A recent survey on these phenomena has been given by Booker [1958]. The so-called scintillations which are observed on most frequencies are quick fluctuations of received radio star intensity and phase [Lawrence, 1958].

They are of ionospheric origin and should decrease in intensity as $1 / f^{2}$, in agreement with the dispersion formula eq (1). Scintillations are very rarely observed in daytime (with the exception of Australia); the scintillation index has a clear maximum at night. The seasonal variation follows that of the ionospheric phenomenon of "spread $F$." The scintillation index goes approximately with sec. $\alpha_{\mathrm{T}}$; i.e., it is smaller for steeper incidence. The irregularities causing scintillations are elongated in shape, alined with the magnetic field with dimensions less than 1 $\mathrm{km}$ across the field but several $\mathrm{km}$ along it. Good correlations have been found with the occurrence of "spread F" in England and near the equator, but apparently not in Australia [Booker, 1958].

As to the geographical distribution it seems that polar and equatorial scintillation bave different statistics. Polar stations on both hemispheres show better correlation among themselves and with the occurrence of aurorae [Aarons et al., 1958] than they do with an equatorial station [Brenan, 1960]. In fact spread $F$ has a positive correlation with the magnetic index at high latitudes [Booker, 1958] while the correlation is negative near the equator [Koster and Wright, 1960]. The equatorial type of spread $F$ is a quiet nighttime phenomenon, completely different in origin from the high latitude type which occurs with magnetic perturbations.

The intensity of the fluctuations depends on frequency, elevation angle, and geophysical factors. The scintillation phenomenon is not limited to lower frequencies. At rather high latitude even on 915 $\mathrm{Mc} / \mathrm{s}$ intensity fluctuations up to 50 percent have been observed; at low elevation they are quite common. The fading frequency increases with aurorae and geomagnetic $K$-index [Ko, 1960]. In the auroral zone scintillations on $223 \mathrm{Mc} / \mathrm{s}$ have been observed in cases where an active aurora was present in the line of sight to the radio star [Benson, 1960].

2.2. The explanation of the scintillations is surely given by irregularities at rather high levels, certainly higher than $100 \mathrm{~km}$; most authors feel that the level lies at or above the ionizations maximum of the F2-layer. It is difficult to determine this level only from radio-astronomical observations.

As the phenomenon occurs predominantly at night, it is not probable that an additional ionization could be the cause. Rearrangement of existing ionization is the most probable theory, but it seems that the turbulence has a character that corresponds more to that of the $E$ region. If a turbulent electrical field existed at the dynamo level it could be transferred to the $F$ region by the magnetic field and there cause the irregular distribution of ionization [Dagg, 1957]. Besides the spectrum often seems to have rather discrete components, so that a more systematic structure than in ideal turbulence should be present [Gruber, 1961].

If rearrangement of ionization along the magnetic field lines is the cause of the phenomenon, a rather unusual optical situation must result. Waves propagating nearly along the magnetic field lines could be reflected by ionization concentrated along these. For lower frequencies the system acts as a sort of lens giving quasi-optical effect of focusing along the axis (fig. 9) [Rush and Colin, 1958].

On the other hand, with this theory the scintillation effect should be extremely aspect sensitive; in temperate latitude the maximum effect should be observed at a rather high elevation while the observations seem to prove a monotonic increase of scintillation intensity with decreasing elevation angle [Booker, 1958].

2.3. While radio star scintillations have only been studied at a few sites on the globe, satellite signals

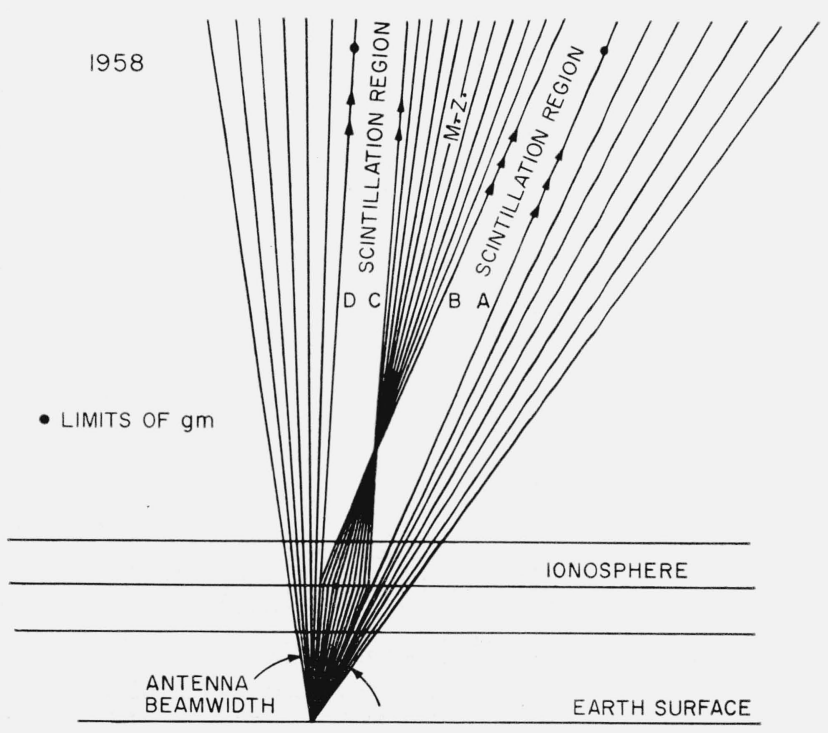

Figure 9. Quasi-focusing by reflection from field-alined ionization. 
have been received at many places in the last years and the characteristic features have been determined. Scintillations can be seen on almost every sort of record: Doppler-curves (frequency versus time) show either irregularities [Liszka, 1959; Arendt, 1960] or a change in frequency as shown on the record of figure 10. Similar irregularities have been observed with direction finders. But the most characteristic change occurs on field-strength records. Undisturbed records show a very regular Faraday fading with deep minima as can be seen in the center of the record, figure 11. If, however, scintillation appears, the character of the amplitude curve changes abruptly. A quicker and irregular fading appears with phase and polarization changes. The signal is no more coherent in that case. For this reason very deep fading minima do not occur during heavy scintillation. This can be seen from the record, figure 12, taken at Kiruna (Sweden) [Aarons et al., 1961].

By collaboration of a group of European stations scintillation zones could occasionally be determined. There seems to be a pronounced preference for them to occur in northern Europe more often than at lower latitudes. At Cambridge (England) scintillation was not observed when the satellite was at lower latitude than the receiving place [Kent, 1959].

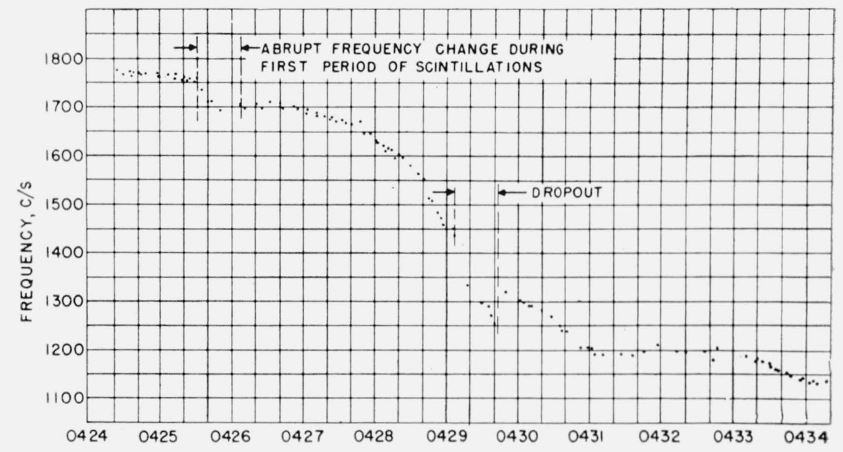

Figure 10. Doppler-curve (1958 Delta II, $20 \mathrm{Mc} / \mathrm{s}$, Paris) with scintillation effect and dropout.

The explanation could be that the true distribution of scintillation regions was centered somewhere near the auroral zone. It could also be that by the aspect sensitivity a preference for the direction of the magnetic field exists [Mawdsley, 1960]. The discussion has been closed by Frihagen and Tröim, [1961a and b.] With the statistical representation shown in figure 13, these authors were able to demonstrate that for a high latitude station scintillations

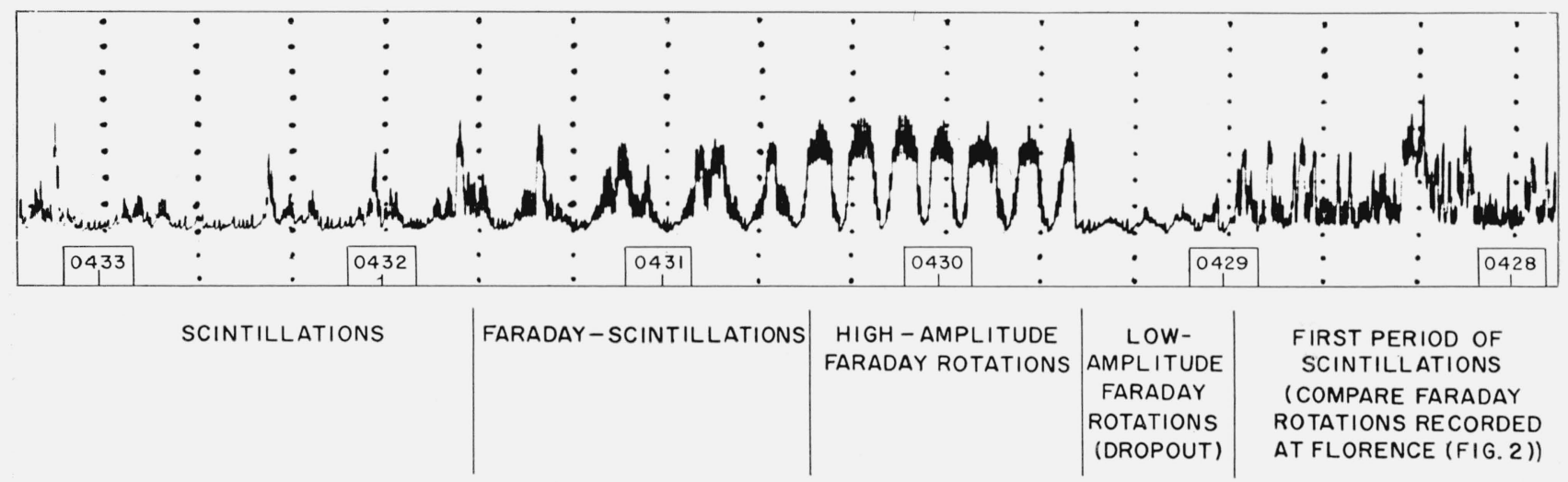

Figure 11. Dropout preceded by scintillation in an amplitude record (1958 Delta II, 20 Mc/s, Jodrell Bank).

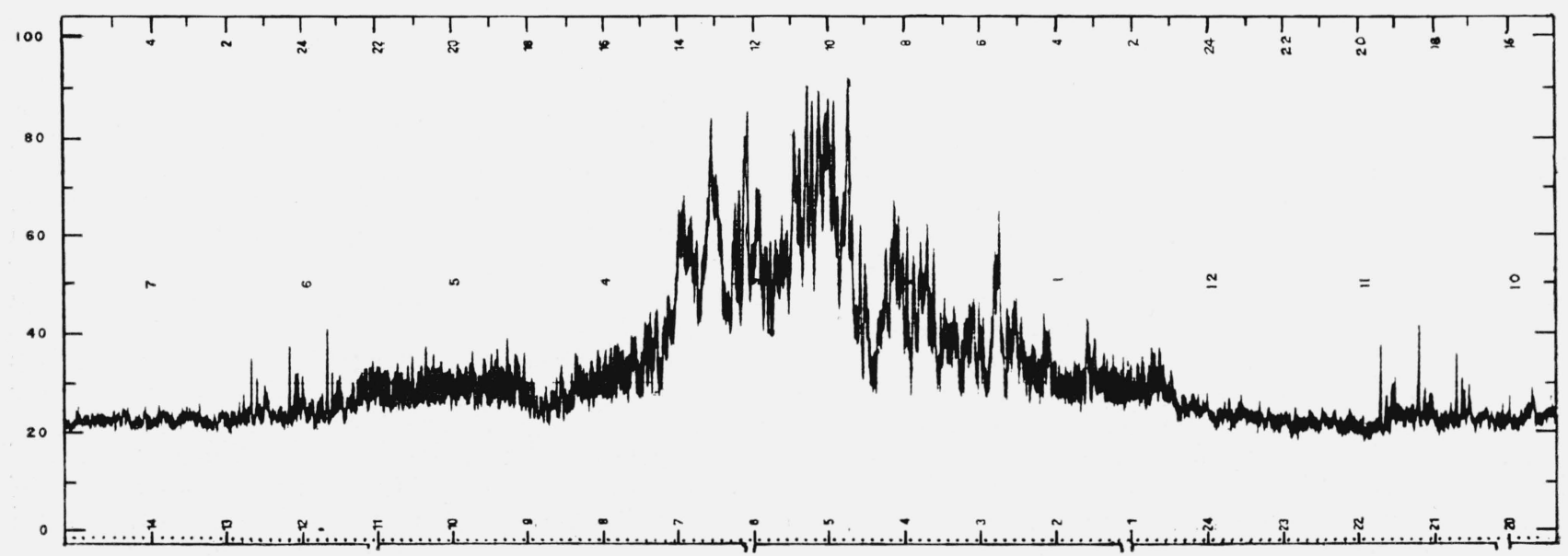

Figure 12. Scintillation completely destroying Faraday fading (1958 Delta II, 20 Mc/s, Kiruna). 


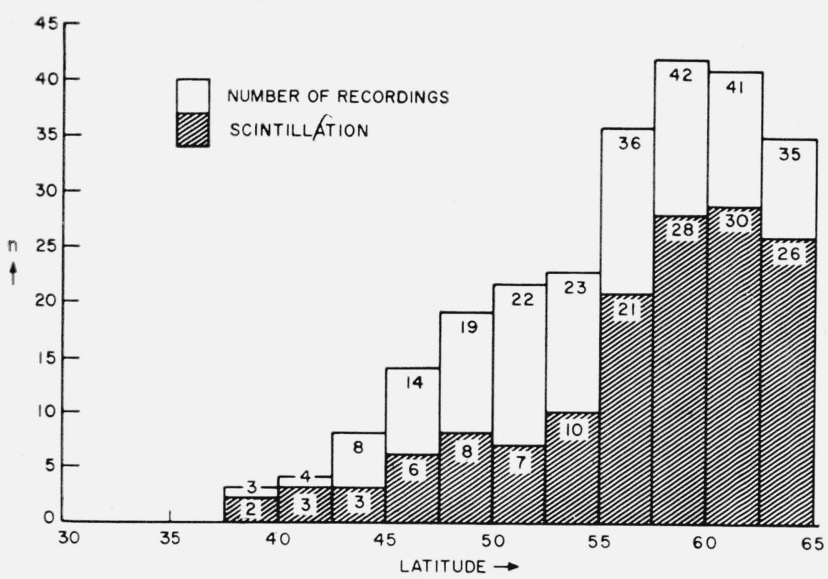

Figure 13. Scintillation statistics as function of latitude of satellite (observed at Oslo-Kjeller).

were occasionally observable when the satellite was south of the station. The distribution shows, however, a maximum near the auroral zone. (Note that these observations have been made with a satellite going not higher than $65^{\circ} \mathrm{N}$.)

This seems to be in agreement with the observations of radio astronomers who found at high latitudes a positive correlation of scintillations with magnetic and auroral perturbations. An intercomparison has been made in the auroral zone; $223 \mathrm{Mc} / \mathrm{s}$ radio star scintillation was often stronger than the satellite signal scintillation on $20 \mathrm{Mc} / \mathrm{s}$. [Parthasarathy and Reid, 1959.] This is a very important result as it seems to be in contradiction with the normal decrease of refraction influence with frequency as shown by eq (1). It may be that the direction influence is more important in the auroral zone than at lower latitudes. Therefore intercomparison experiments looking for scintillation at very different frequencies are highly desirable.

Observations on rather low frequencies can be influenced by skip phenomena. It may be that some of the phenomena observed on $20 \mathrm{Mc} / \mathrm{s}$ which are described as scintillations are caused by interference fading between different propagation paths. An attempt has been made to determine the skip zone radius in this way [Nakata, 1959].

Another interesting observation has been made at medium latitude during the days following the "Argus" high altitude explosion. During these days scintillations occurred less often than before [Hutchinson and Arendt, 1960; Arendt, 1960b]. Similar observations from low latitudes have not come to the knowledge of the author.

2.4. With satellite signals the height of the scintillation region can better be determined than with radio-astronomical observations. At temperate latitude the occurrence of scintillations decreased when the height came to $200 \mathrm{~km}$ or less [Slee, 1958]. It is, however, probable that different conditions are present in and near the auroral zones. The apparent drift velocities can be determined with the help of several receiving antennae. By intercomparison with the satellite speed the height should be found by purely geometrical reasoning. The irregularities were found to be fairly elongated with roughly $135 \mathrm{~m}$ length (along the magnetic field) and a thickness of only $10 \mathrm{~m}$ [Frihagen and Tröim, 1960].

2.5. With respect to propagation, scintillation must be considered as an attenuation influence with energy loss due to a sort of scatter. This means, of course, that scatter propagation should be possible outside the line of sight if the antenna is directed to a scintillation zone. The importance of scintillation phenomena on propagation noise has not yet been investigated.

\section{Ionospheric Absorption}

3.1. Ionospheric absorption has first been observed on frequencies which are reflected from the ionosphere. For observations at vertical incidence this signifies $f<f_{c}$. More recently radio-astronomical observations on higher frequencies $f>f_{c}$ have thrown some light on absorption phenomena for waves penetrating through the ionosphere. On HF frequencies of the order of $20 \mathrm{Mc} / \mathrm{s}$ true absorption is normally due to a superposition of lower layer absorption and $F$ region absorption. Both contributions can be separated roughly by considering (after reduction to standard conditions) the daily variation of cosmic noise received on a directive antenna [Mitra and Shain, 1953]. At low and temperate latitudes the contribution of the lower regions $D$ and $E$ follows the height of the sun (given by $\cos \chi$ ) with a short delay only. Therefore, that part which varies with $\cos \chi$ and disappears at night should be due to lower layers. (This is the same absorption process which is responsible for absorption of reflected waves.) The rest is normally attributed to the $F$-region, and it has a rather good correlation with the ionization of the F2-layer. Some authors have tried to separate from this rest a contribution following exactly the critical frequency $f_{0} F_{2}$ and a second rest of unknown origin. It seems, however, that the parameter effective for true $F 2$-absorption is a combination of maximum electron density and layer thickness which both vary considerably and in some way independently. As to the mechanism of the absorption process, it is now clear that the effective collision number in the lower layers is that between electrons and neutral molecules while it is mainly with positive ions in the $F$-region [Majumdar, 1937; Argence et al., 1952]. A rather recent table of collision frequency data is given by Nicolet [1959]. Therefore absorption depends in a different way on ionospheric conditions and on frequency in lower and higher ionospheric regions. $F$-region absorption depends very critically on the electron density of that region so that the highest absorption values are found together with the highest electron density values.

For normal conditions the absolute value of attenuation is not very large - up to a maximum of $1 \mathrm{db}$ on $20 \mathrm{Mc} / \mathrm{s}$ at vertical incidence [Mitra and Shain, 1953; Blum, Denisse, and Steinberg, 1954]. This means a maximum of $6 \mathrm{db}$ at horizontal inci- 
dence. An absorption of this importance can have some influence on the shape of the standard diagram. A certain directivity upwards should be produced on the lower $\mathrm{HF}$ frequencies in daytime provided that the $F$ region ionization is important (see fig. 26). On higher frequencies the attenuation due to true ionospheric absorption is much smaller, nearly negligible. For this reason it has not yet been possible to determine it from field-strength observations of satellites, present antenna arrangements introducing larger changes during the passing of a satellite.

3.2. In the auroral zones much larger ionospheric absorption can occur. On $30 \mathrm{Mc} / \mathrm{s}$, for example, a vertical incidence attenuation up to $6 \mathrm{db}$ is observed under auroral conditions while the normal value is only $0.5 \mathrm{db}$. The increased absorption is well correlated with the magnetic character figure [Little and Leinbach, 1958].

A special very important absorption phenomenon is now known as "polar cap absorption" [Reid and Collin, 1959]. It occurs after solar flares with type IV radio emission which is a very rare event. Polar cap absorption occurs in the whole polar cap, not only in the auroral zones, and lasts often several days with a preference for daylight hours [Little and Leinbach, 1958]. The origin of this absorption seems to be ionization at low altitudes, between 50 and 60 $\mathrm{km}$ only, caused by solar proton emission [Hultqvist and Ortner, 1959].
3.3. Satellite observations occasionally show sudden drop-outs; different theories have been proposed for their explanation. An intercomparison experiment has been made with simultaneous observations between a group of European and American stations [Aarons et al., 1960]. It could be shown that there are two classes of such events. One is observed exactly simultaneously at all stations; for the other one, the reports of widely spaced stations are different with respect to time and importance.

Examples of the second class are given in figures 14 and 15. In figure 14 the record of Florence (Italy) shows very regular Faraday fading; also regular fading occurs at Jodrell Bank (England) but with slight scintillation superposed. At Kjeller (Norway) (different time scale) Faraday fadings and scintillations occur alternatively but the field strength disappears for about $1 \frac{1}{2} \mathrm{~min}$. For Florence and Jodrell Bank the field strength decreases more slowly; it disappears completely at Jodrell Bank but not at Florence. Another case is shown in figure 15. A clear dropout of $1 / 2 \mathrm{~min}$ is visible on the Kjeller record; at Kiruna (Sweden) the increase of field strength occurred some $10 \mathrm{sec}$ later while at Jodrell Bank only a small decrease of field strength is visible (earlier than the Kjeller dropout). The regions where the attenuation probably occurred can be determined geometrically if a plausible assumption as to its height is made. It was found
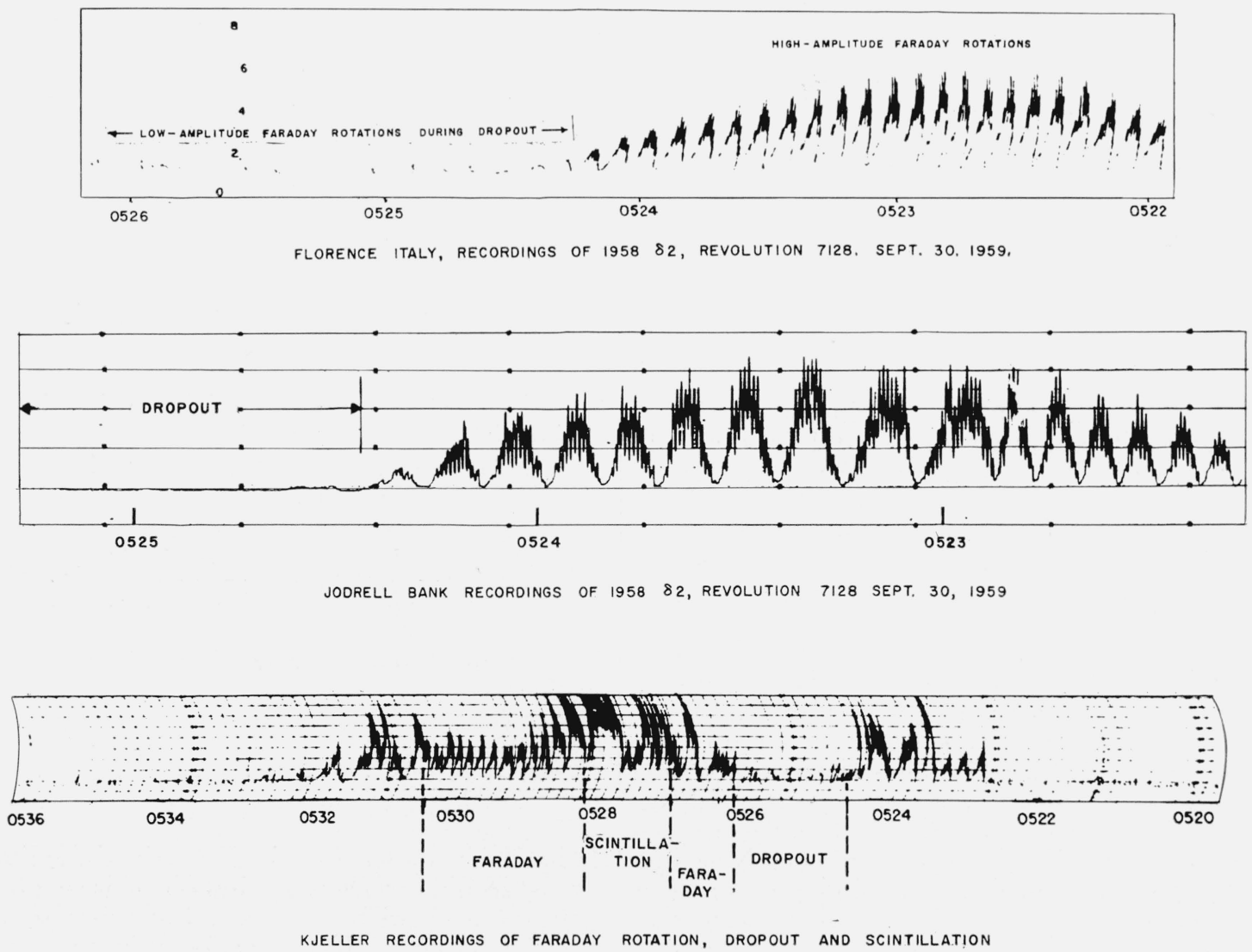

Figure 14. Amplitude records of three stations (20 $\mathrm{Mc} / \mathrm{s}$ ) showing a dropout. 

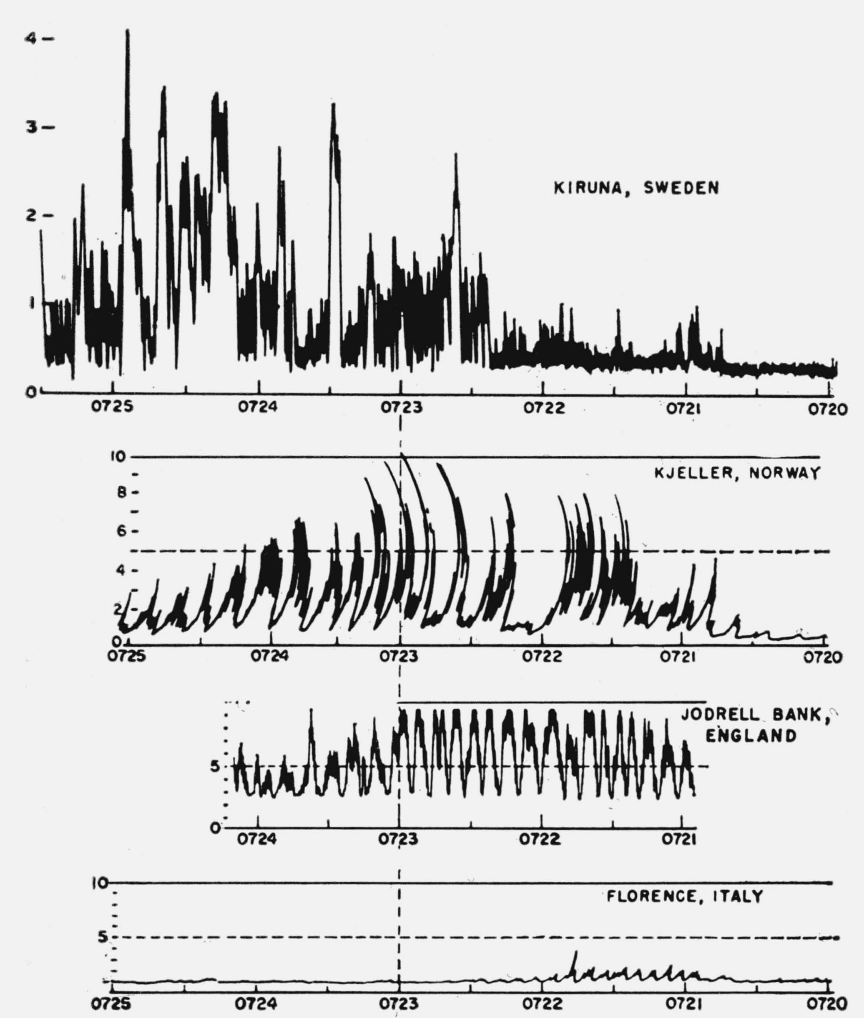

Figure 15. Amplitude records of four stations (20 $\mathrm{Mc} / \mathrm{s}$ ) showing dropout mainly in Sweden and Norway.

that these regions (like the scintillation regions) have a tendency to be found at higher latitudes. They could be identical with the areas of high ionization in the $D$-region due to auroral perturbations [Whitney et al., 1960].

The first class of dropouts cannot be a true propagation effect as it occurs very accurately and simultaneously at different stations. An example is shown in figure 16 [Aarons et al., 1961]. This dropout can be seen at all stations even at the latitude of Florence; it can also be seen on the second harmonic of the transmitted frequency (see uppermost record, Breisach). This must be an effect at the satellite transmitter. Another hypothesis was a detuning of the antenna when the satellite is passing through highly ionized areas [Whitney et al., 1960]. It was stated that the dropouts occurred only at higher latitudes. Figure 17 shows the geographical distribution of the location of the satellite during dropouts as observed in northern Sweden [Liszka and Hultqvist, 1961]. (The limit of $65^{\circ} \mathrm{N}$ is imposed by the satellite orbit.) It is evident that the zone of occurrence has some relation with the auroral zone. This does not necessarily mean that the auroral phenomena cause the changes on board of the satellite. The auroral zones are found below the horns of the outer van Allen belt, so that a radiation influence is also possible. A recent hypothesis is that the crystal oscillator is changing its frequency when it is hit by hard cosmic radiation [Liszka, 1961], with reference to Beckman [1958], and Renius and Rees [1960].

It is in agreement with this theory that the frequency seems to be always falling during these dropouts, for example, figure 18 [Liszka and Hultqvist, 1961].

\section{Specific Phase Effects}

4.1. Phase observations are much easier with coherent satellite signals than with mostly incoherent noise from radio stars. We have just stated (see sec. 2.3) that a certain class of refraction irregularities can destroy the coherency. In all other cases the phase of the signal is an interesting parameter. Three such parameters are measurable: the frequency (which is the time derivative of the phase), the polarization (which is essentially given by the phase difference between the two magneto-ionic components), the differential phase (between two phase-locked frequencies).

The decisive expression is always the phase integral

$$
\int_{r_{S}}^{r_{T}} d \boldsymbol{r} \cdot \boldsymbol{k}
$$

where $\boldsymbol{r}_{S}$ is the radius vector to the satellite, $\boldsymbol{r}_{T}$ that to the receiving place, $\boldsymbol{r}$ that of a point on the ray and $\boldsymbol{k}$ is the wave vector $=\frac{\omega}{c_{0}} \boldsymbol{n}$ ( $c_{0}$ velocity of light, $\boldsymbol{n}$ vectorial refraction index, i.e., a vector in the direction of the wave normal with the absolute value $n$, w angular frequency of the wave). The field at the receiving site is then given by

$$
\boldsymbol{E}_{T} \propto \exp \left(i \int_{r_{\boldsymbol{S}}}^{r_{T}} d \boldsymbol{r} \cdot \boldsymbol{k}-i \omega t\right)
$$

The different parameters which can be observed are deduced from this expression.

4.2. The Doppler effect is observed by measuring the frequency $f^{\prime}$ of the received signal. It is given by

$$
2 \pi f^{\prime}=-\frac{d}{d t} \arg \boldsymbol{E}_{T}=\omega-\frac{\omega}{c_{0}} \frac{d}{d t} \int_{r_{S}}^{r_{T}} d \boldsymbol{r} \cdot \boldsymbol{n}(\boldsymbol{r}) .
$$

With respect to the transmitted frequency $f=\omega / 2 \pi$ we have

$$
c_{0} \frac{f^{\prime}-f}{f}=\frac{d \boldsymbol{r}_{S}}{d t} \cdot \boldsymbol{n}_{s}-\frac{d \boldsymbol{r}_{T}}{d t} \cdot \boldsymbol{n}_{T}-\int_{r_{S}}^{r_{T}} \frac{d}{d t} d \boldsymbol{r} \cdot \boldsymbol{n}(\boldsymbol{r})
$$

It has been shown that in a stratified medium (with an isotrophic refraction index) this expression is only determined by the conditions at the terminals [Weekes, 1958]. The final formula can be written in general orthogonal coordinates [Rawer and Suchy, 

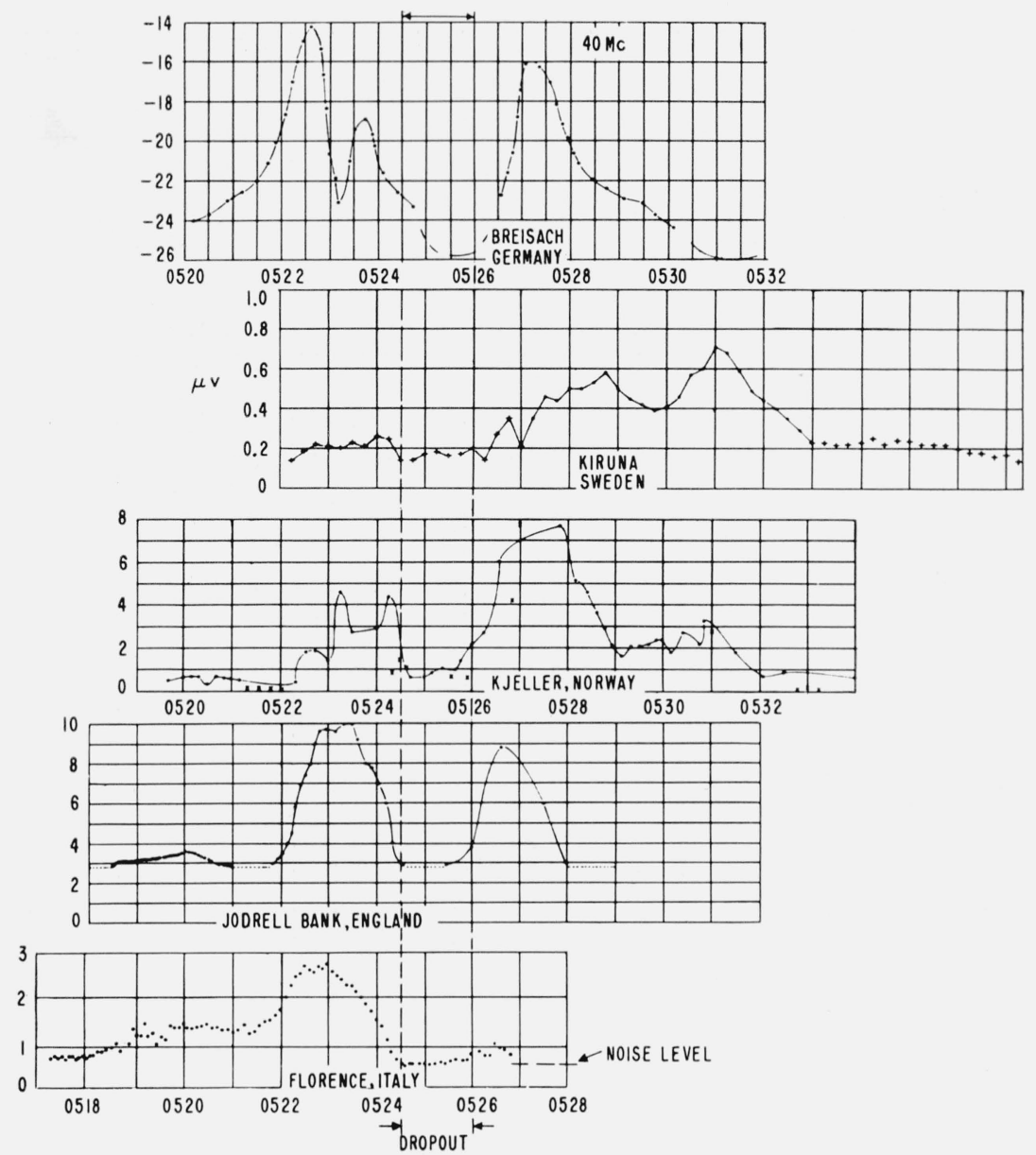

Figure 16. Amplitude records of five stations (20 Mc/s, but Breisach $40 \mathrm{Mc} / \mathrm{s}$ ) showing simultaneous dropouts.

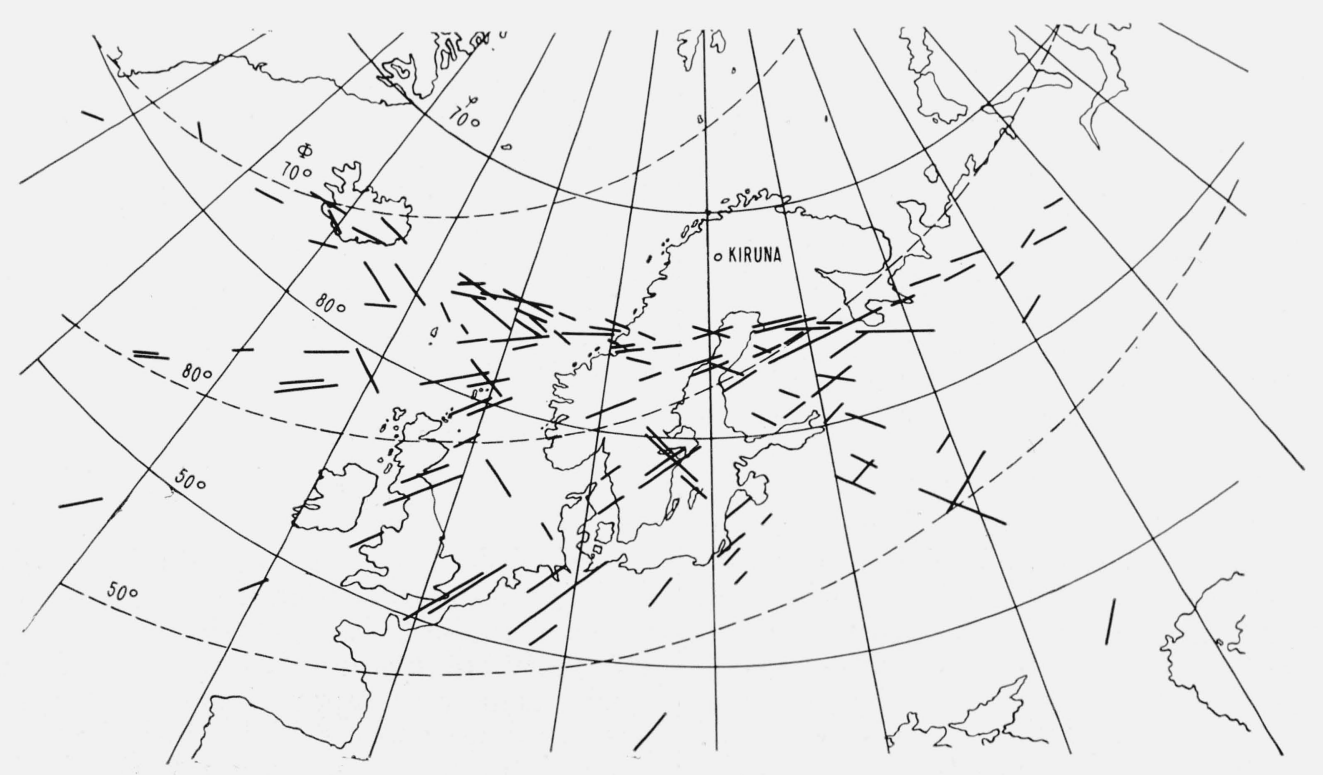

FiguRE 17. Geographical distribution of dropouts recorded at Kiruna, Sweden. 


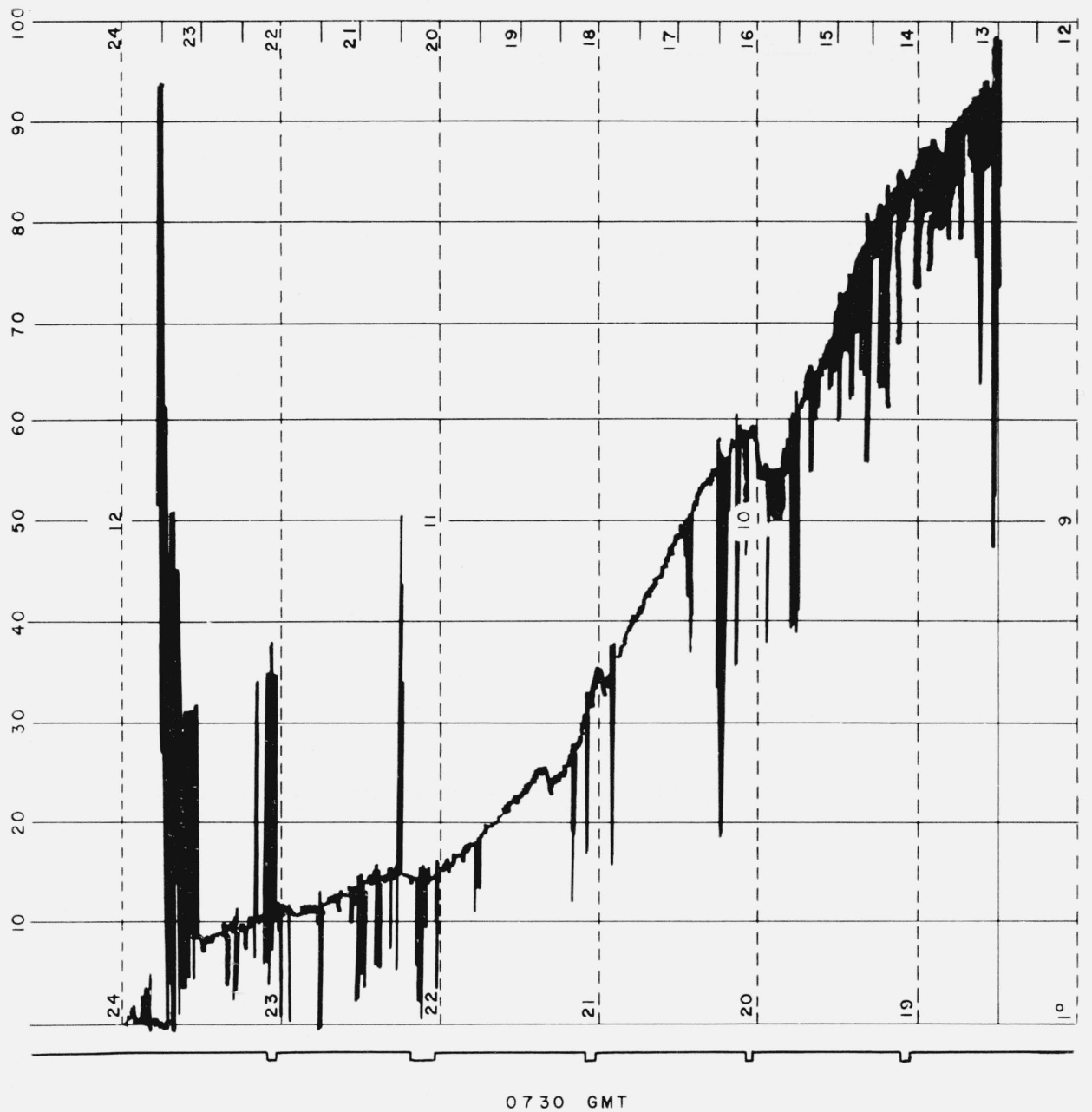

Figure 18. Doppler curve with frequency droppings (2O Mc/s, Kiruna).

1962]. In the special case of cylindrical coordinates $r, \phi$ one has finally

$c_{0} \frac{f^{\prime}-f}{f}=-\sqrt{n_{S}^{2}-\left(\frac{r_{T}}{r_{S}} \sin \alpha_{T}\right)^{2}} \frac{d r_{S}}{d t}-r_{T} \sin \alpha_{T} \frac{d \phi}{d t}$.

Apparently the values of the refractive index $n$ existing between both terminals $S$ and $T$ do not appear in this formula, but they determine the value of the angle at the receiving station, $\alpha_{T}$.

It is clear from (8) that the Doppler effect gives us a tool to obtain some information on the refractive index and thus on the electron density. These relations can give directly $\int d r N$, unfortunately only when some important simplifications are valid. One of these is the validity of Sellmeier's formulawhich is only true for rather high frequencies, the other is that the curvature of the laver can be neglected-and this is never true. For these reasons the accuracy of determinations of the electron density integral from the Doppler curve is not good. The ionospheric effect on the Doppler curve is only a second order effect and alwavs small so that the experimental accuracy is a serious limitation. A large number of publications are concerned with Doppler measurements; they can be found in the bibliography.

Even with intercomparison of two frequencies the accuracy is not yet good enough [Hibberd and Thomas, 1959; Ross, 1960; Kelso, 1961]. This will become better when very accurate, phase-locked multifrequency satellites can be observed.

4.3. The Faraday rotation $\Omega$ is given by the difference in phase of the two magneto-ionic components ${ }_{0}$ and ${ }_{x}$ :

$$
\Omega=\frac{\pi f}{c_{0}}\left\{\int_{r_{S}}^{r_{T}} d \boldsymbol{r} \cdot \boldsymbol{n}_{0}-\int_{r_{S}}^{r_{T}} d \boldsymbol{r} \cdot \boldsymbol{n}_{x}\right\} .
$$

In principle both components have different ray paths; therefore the accurate calculation becomes rather complicated, in particular when the inhomogeneity of the medium is taken into account [Kelso, 1960]. Different approximations have been proposed. The simplest of them is a first-order approximation introducing the simple longitudinal approximation to the complete dispersion formula. 
In this approximation $\Omega$ is directly proportional to the integral over the electron density $N$. The first evaluation has been made with this approximation [Browne et al., 1956; Bowhill, 1958; Arendt, 1959b; Schmelovsky, 1960]. The effect of an important spin of the satellite has been considered by Roger and Thomson [1960]. Unfortunately the first order approximation is not good enough, at least for frequencies below $100 \mathrm{Mc} / \mathrm{s}$. This is due to the fact that a differential effect is considered; it can be important on frequencies for which the magnetic influence on the ray path itself is completely negligible. A second-order approximation has been used by Yeh [1960]. Higher-order approximations have been introduced by Argence et al. [1960], and by Garriot, Little, and Lawrence [1960]. The variable direction and intensity of the magnetic field along the ray path has an important influence. The effect disappears when the propagation direction is orthogonal to the local magnetic field; the locus (of the satellite positions) where this condition holds in the central part of the $F$-region has a shape similar to a hyperbolic curve, and its apex lies (magnetically) north from the receiving site. Higher-order approximations are surely needed if the orbit comes to the neighborhood of this locus.

The Faraday effect is a first-order effect and therefore much more usable for ionospheric measurements than is the Doppler effect. Seen as an influence on propagation, the difficulty with the Faraday effect is that it is highly variable with ionospheric conditions and direction. The regular fadings with deep minima are rather dangerous for certain communication systems. The fading could be avoided with circular polarization of the receiving antenna. If this is not done the polarization changes are yet remarkable on rather high frequencies: such a slow fading rate can be particularly dangerous causing long periods of silence. Even at a frequency of 1 $\mathrm{Gc} / \mathrm{s}$ a complete rotation of the plane of polarization is possible under the worst conditions. Only on frequencies which are large compared to this can the value of Faraday rotation be neglected in all cases.

4.4. Observations of the Faraday effect from satellites have been made at different locations [Daniels and Bauer, 1958; Thomson, 1958; Aitchison et al., 1959b; Blackband et al., 1959; Parthasarathy and Reid, 1959; Blackband, 1960; Garriot, 1960; Hill and Dyce, 1960; Little and Lawrence, 1960; Schmelovsky, 1960; Yeh and Swenson, 1961]. Typical records are shown in figures 19 and 20 [Hess and Rawer, 1960]. Figure 19, taken when the satellite was above the $F 2$-maximum, shows a very regular Faraday fading with 17 minima per min. The systematic variation of the envelope is due to the receiving antenna diagram. Figure 20 has been obtained under similar conditions as to the state of the ionosphere and the geographical position of the satellite but the height of this latter was now about $100 \mathrm{~km}$ below the $F 2$-maximum. For this reason the total effect is now quite small, only 3 minima per minute. The observed amplitude curve depends mostly on some other influences also, in particular the diagrams of the antenna on the satellite and on ground. (The situation becomes particularly complicated when the satellite has no linear polarization.) Only for rather low frequencies like in figure 19 the Faraday effect gives the quicker fading. On higher frequencies the lobes of the receiving antenna may be more prominent than the few Faraday fadings; in that case only a part of the observed minima is due to Faraday effect.

An interesting record obtained with the third Soviet space probe is shown in figure 21 [Vitkevich et al., 1961]. In that case the transmitting antenna had linear polarization but two crossed dipoles were used as receiving antenna. The upper and central curve of figure 21 show clearly a $90^{\circ}$ phase difference as it is normal for the reception of rotating polarization. The record covers about $1 \mathrm{hr}$. The regular fades are mainly due to the variable direction of the ray passing through the ionospheremore than to the increase in electron content along the path. Care must be taken in the interpretation of such curves as only changes of $\Omega$ are observable; in particular at the points where $\Omega$ has a maximum or minimum the counting of the minima must be inverted if correct electron density data shall result.

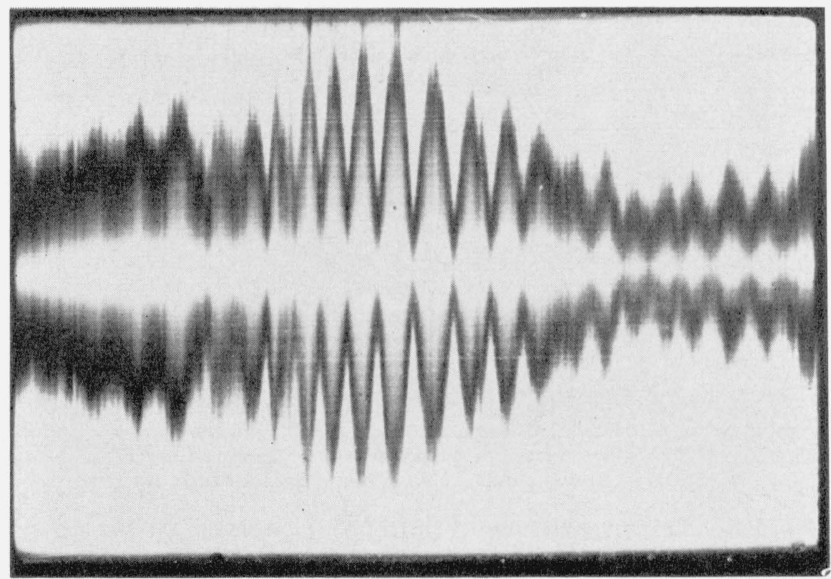

FIGURE 19. IF-amplitude record showing regular Faraday fading $(1958$ Delta II, $40 \mathrm{Mc} / \mathrm{s}$, Breisach).

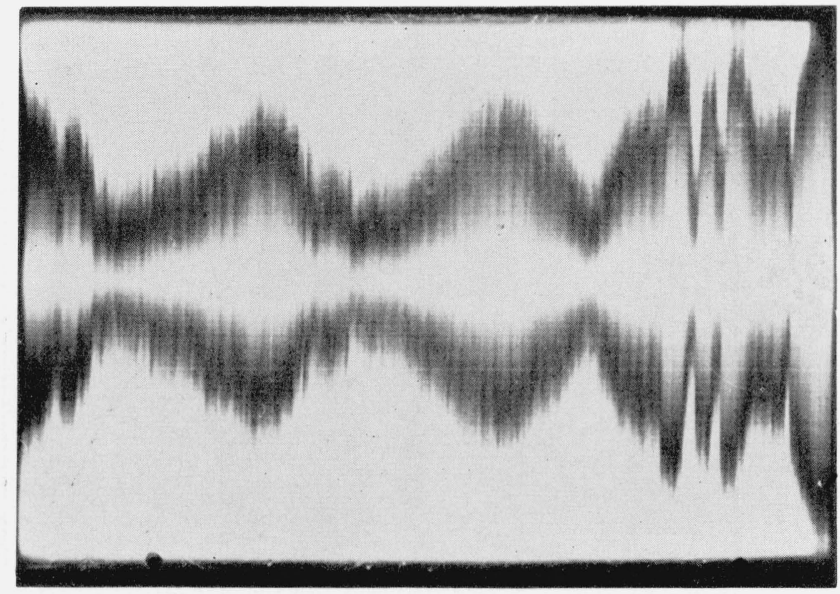

FiguRe 20. IF-amplitude record in similar position to figure 19 showing slow Faraday fading (satellite below F2 layer). 


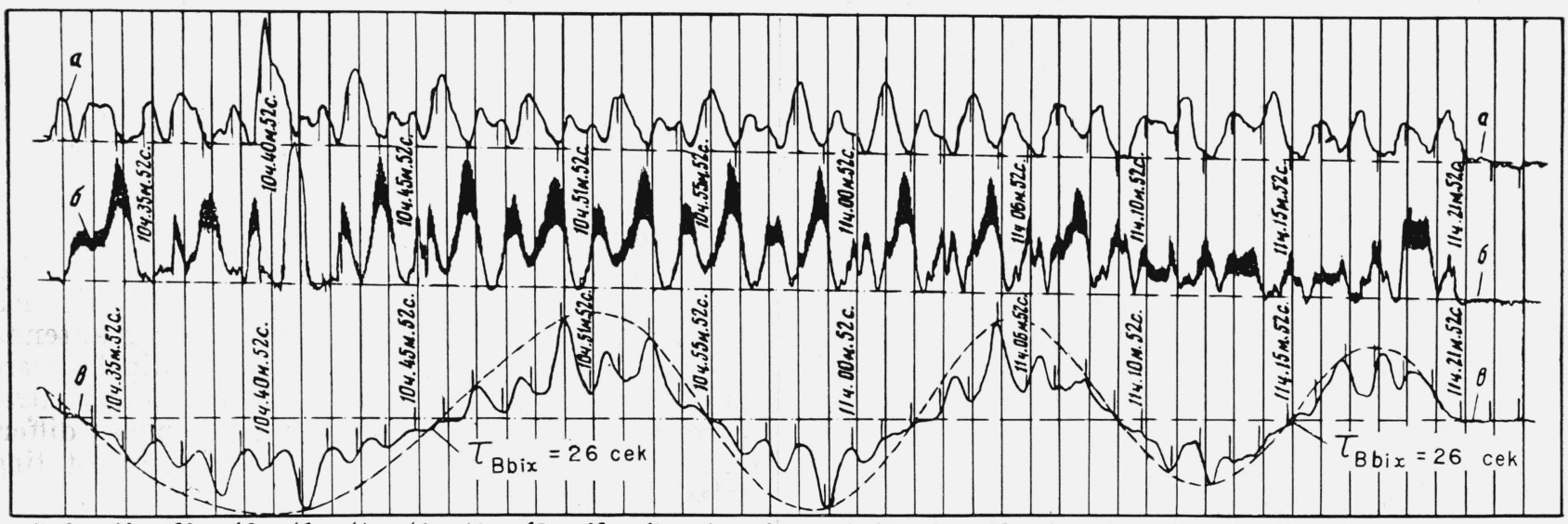

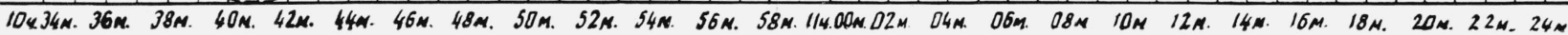

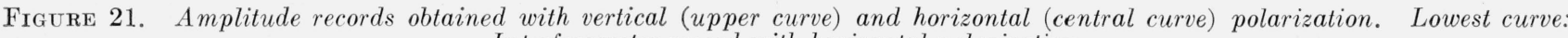
Interferometer record with horizontal polarization.
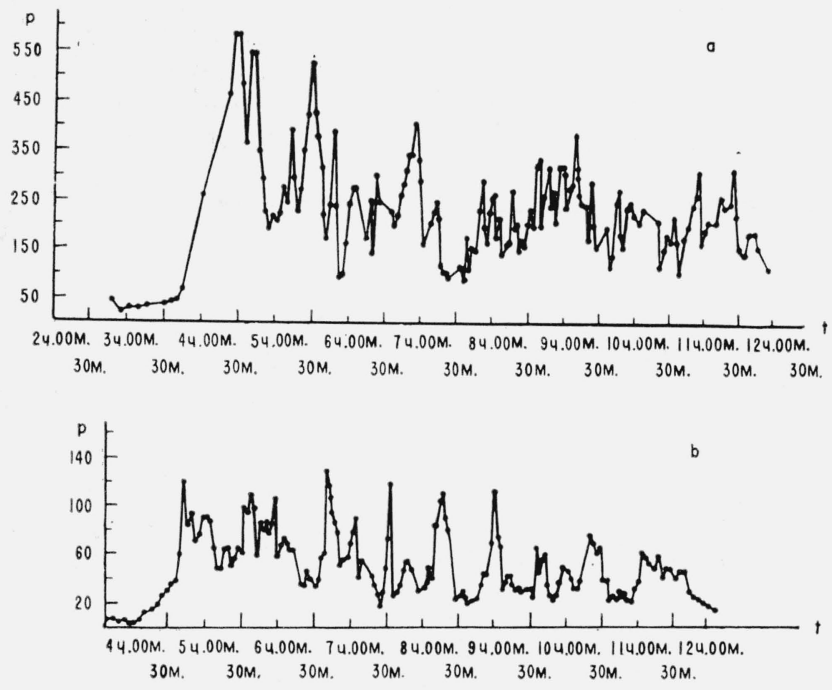

Figure 22. Amplitude records of signals from first soviet space probe (20 Mc/s; upper curve 3.1.59; lower curve 4.1.59).

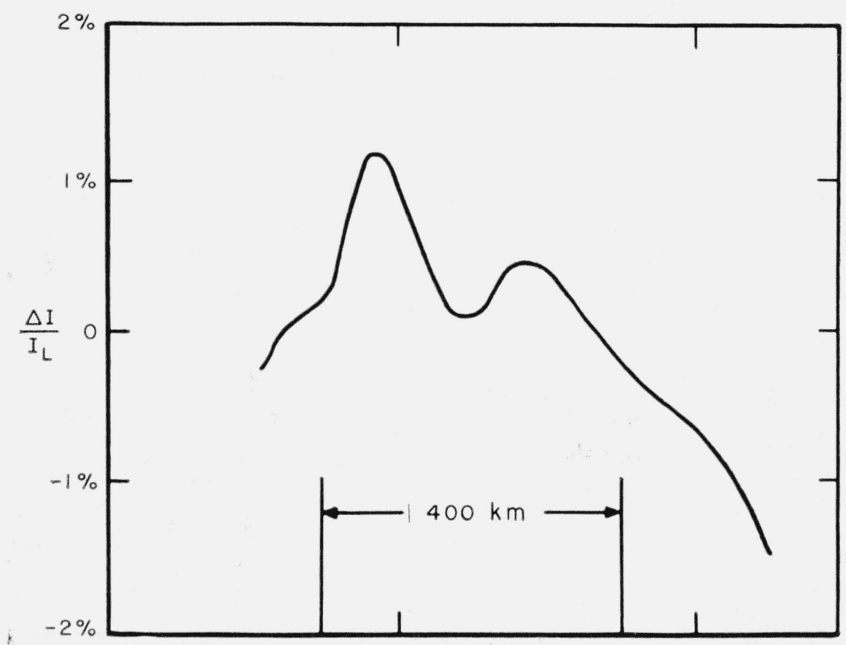

FIGURE 23. Variation of subsatellite ionospheric electron content obtained from Faraday effect.
Reception from space probes does not always show the very regular behavior of figure 21. The field strength curves shown in figure 22 have been obtained with the first Soviet space probe; each diagram covers about $8 \mathrm{hr}$ [Vitkevich et al., 1961]. It is evident that we can not yet give a detailed explanation distinguishing the different influences which are effective; antenna diagrams and Faraday fading are among the most important ones, but some unknown other influences seem to be present. This is a subject for further studies.

Normally at the physical interpretation of Faraday records some hypothesis concerning the electron density distribution is introduced so that here also the accuracy has some limitations. Fortunately these hypotheses are not very critical if only the total electron content is looked for. The situation is certainly much better than with the Doppler effect and when the calculations are made accurately enough interesting results can be obtained. As an example, figure 23 shows the variations or subsatellite electron content evaluated from Faraday records; local variations with dimensions of the order of $100 \mathrm{~km}$ can be seen [Little and Lawrence, 1960]. The numerical values of the total subsatellite electron content is largely variable with the ionospheric conditions, i.e., with the hour and with the geographical location. Values between the approximate limits 3 and $40 \cdot 10^{16} \mathrm{~m}^{-2}$ have been cited. Another parameter which has been determined rather often is the ratio of subsatellite electron content to that of the inner ionosphere (i.e., below the $F 2$-maximum) This ratio seems to be very largely variable, between 1.5 and 5 or even 8 .

As only changes of the total rotation can be determined, there is an ambiguity with respect to the absolute value of $\Omega$. It can be removed by intercomparison of two frequencies; otherwise special methods must be used in order to obtain "selfconsistent" data.

Some observations of the Faraday effect have also been made with moon echoes [Evans, 1957; Bauer and Daniels, 1958; Dyce, 1960; Millman and Sanders, 1960]. These results are particularly interesting as 
they give iuformation concerning a very large distance. However, as the electron density is decreasing in the outer ionosphere, the most important contribution to the total rotation occurs in regions rather near to the earth.

\section{Tropospheric Influences}

5.1. Ray deviation by tropospheric refraction which is so important for terrestrial propagation of VHF and UHF waves normally is negligible on these waves for satellite propagation. The reason is that sa tellite communication is nearly always effected with a rather high elevation angle. The effect is only remarkable in the case of a very low elevation angle $\left(\alpha_{T}\right.$ nearly $90^{\circ}$ in eq (2) and (3)). At such angles with radio-astronomical methods, tropospheric scintillation has been observed down to $3 \mathrm{~cm}$ waves [Aarons et al., 1958]. One of the differences between tropospheric and ionospheric refraction is that the refraction index due to free electrons in the ionosphere depends on frequency while the polarization of neutral molecules in the troposphere is due to bound electrons and is not seriously frequency dependent in the considered frequency range. If we characterize the refraction effect as is usually done by the expression $10^{6} \cdot(n-1)$, the maximum tropospheric value is 300 up to 500 for cases of very high humidity. In the ionosphere considerably higher values occur on frequencies up to $100 \mathrm{Mc} / \mathrm{s}$; during periods of important ionization tropospheric and ionospheric values come to the same magnitude for frequencies of the order of $1 \mathrm{Gc} / \mathrm{s}$. Even then the ionospheric influence is larger except for very low elevation angles (which are rarely used) as the ionospheric layers are much thicker. So the limiting frequency above which tropospheric refraction is more important is of the order of $1 \mathrm{Gc} / \mathrm{s}$ and can even be higher.

For practical applications, scintillation and propagation noise (see sec. 6) may be more interesting influences of tropospheric refraction than ray deviation.

5.2. Tropospheric absorption occurs mainly by molecular absorption of oxygen and water vapor. Recent absorption curves are given in figures 24 and 25 [Straiton and Talbot, 1961]. The high absorption values which are found in the vicinity of the strong absorption lines constitute the upper frequency limit of the "radio-astronomical window" for the time being. For the application of these diagrams some information is needed on the total amount of oxygen and water vapor in the atmosphere. Reduced to one atmosphere (fig. 24) the effective thickness of the total atmosphere is $7.231 \mathrm{~km}$, the part of molecular oxygen is then $1.516 \mathrm{~km}$. (The indication of figure 24 must be multiplied by 1.516 to give the total oxygen absorption at vertical incidence). As to water vapor the partial pressure $e(h)$ decreases with height $h$ approximately as given by Hergesell's formula:

$$
e(h) / e_{0}=10^{-\frac{h}{8 \mathrm{~km}}}\left(1+\frac{h}{6 \mathrm{~km}}\right) .
$$

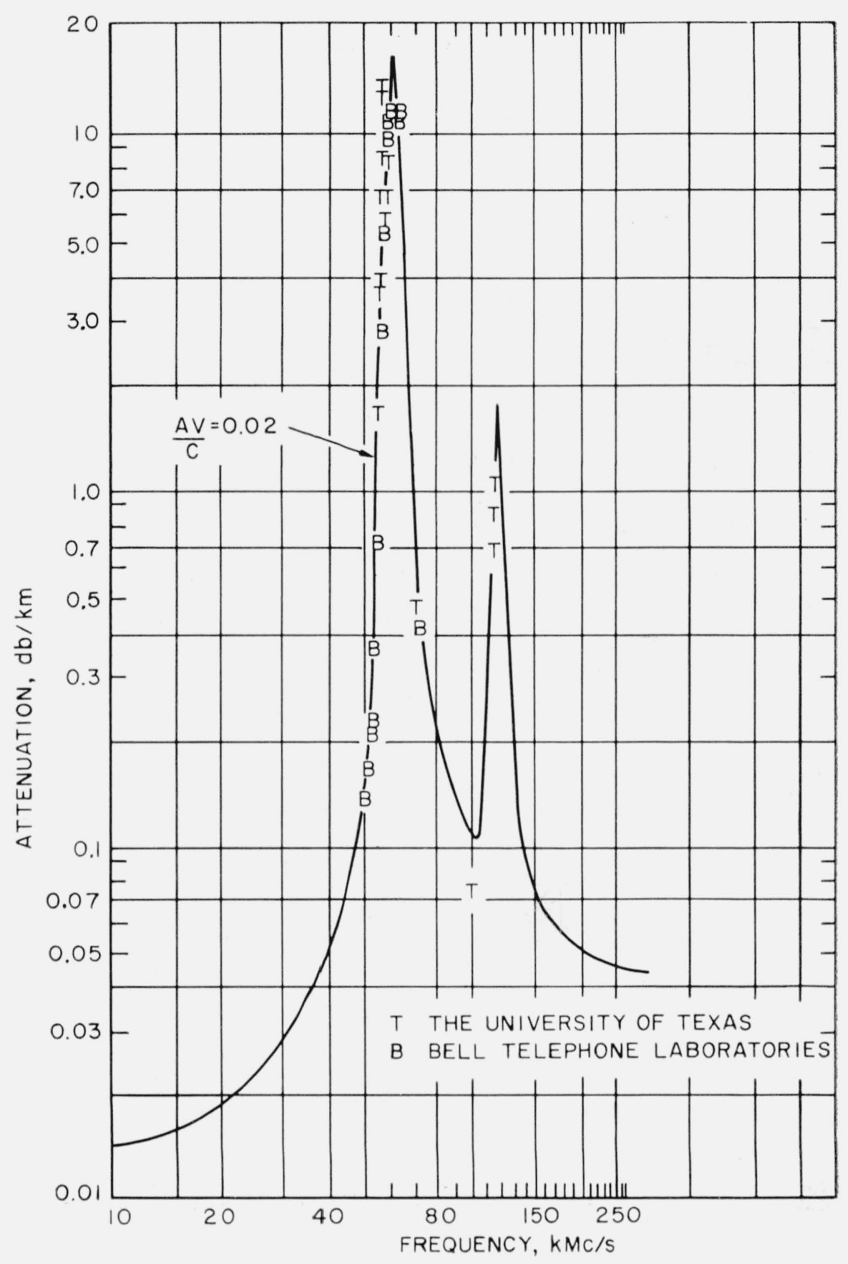

Figure 24. Absorption by oxygen (one atm).

By integration the effective thickness of the water vapor atmosphere reduced to $e_{0}$ is obtained as 4.54 $\mathrm{km}$. (The indications of fig. 25 must be multiplied by 4.54 if the humidity at the ground equals 7.5 $\mathrm{g} / \mathrm{m}^{3}$; otherwise one has to reduce to the true ground value.)

The absorption coefficient in the lower troposphere is also high during precipitation. Effectively the critical value of $1 \mathrm{db} / \mathrm{km}$ is normally reached at about $40 \mathrm{Gc} / \mathrm{s}$ (oxygen line at $60 \mathrm{Gc} / \mathrm{s}$ ). In the case of strong precipitation this limit can be as low as 8 $\mathrm{Gc} / \mathrm{s}$.

At frequencies near these values the total tropospheric absorption at vertical incidence reaches several db; at oblique incidence it can then become very high. Under these conditions the standard diagram clearly shows vertical directivity. Examples are shown in figure 26.

Water vapor absorption has a line near $22 \mathrm{Gc} / \mathrm{s}$ and an extremely strong one at $180 \mathrm{Gc} / \mathrm{s}$. The attenuation due to these lines is variable with the atmospheric content of water vapor. Figure 27 gives the average latitude variation of humidity for different seasons [Hann and Süring, 1936]. The 


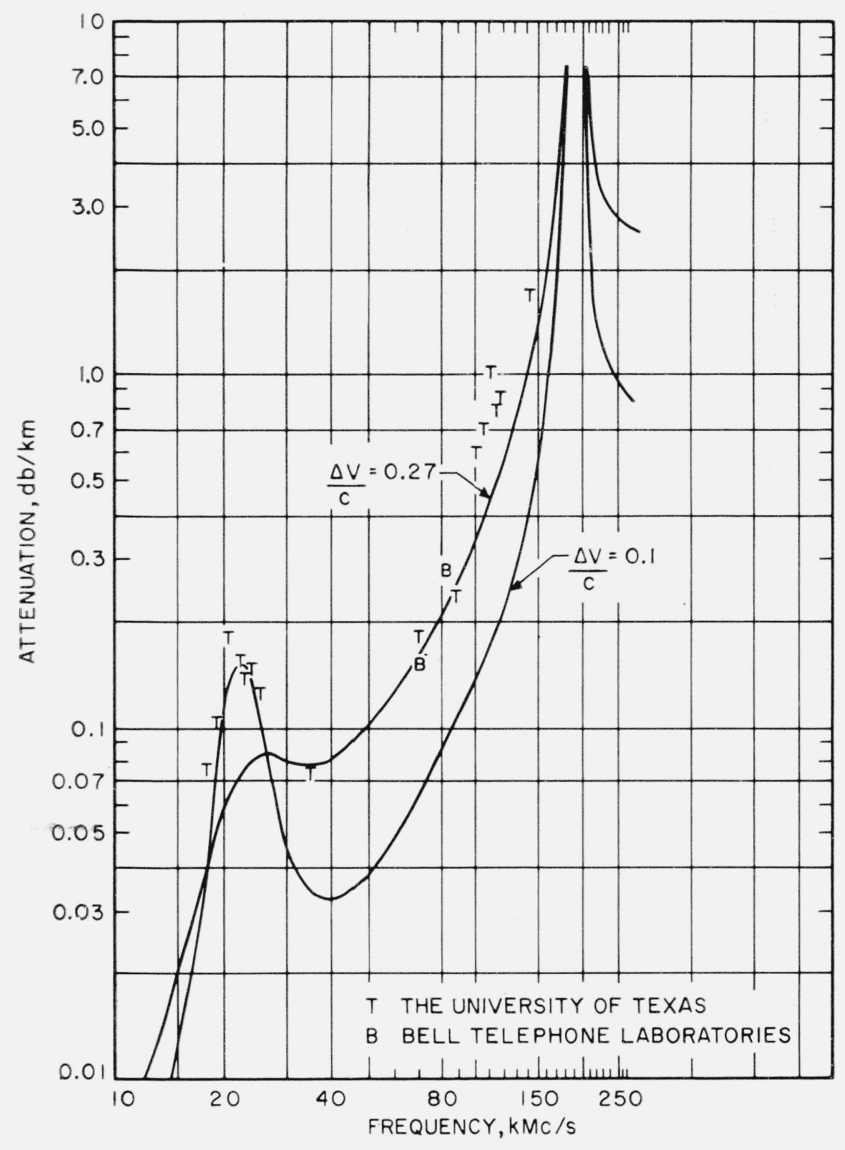

Figure 25. Absorption by water vapor $\left(7.5 \mathrm{~g} / \mathrm{m}^{3}\right)$.

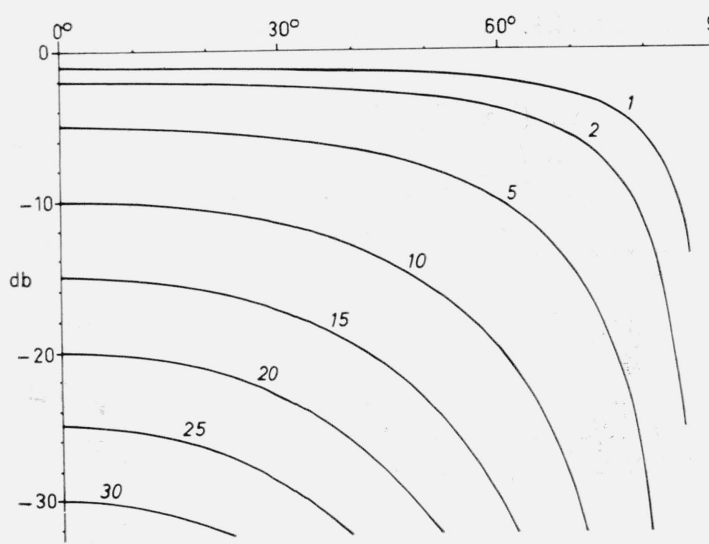

FIgure 26. Standard extraterrestrial diagram for different values of the total vertical absorption as parameter (flat thin troposphere).

highest values occur in the tropical zone, they are about three times larger than at medium latitude $\left(45^{\circ}\right)$.

Seen as a propagation influence tropospheric absorption is negligible on frequencies where the specific attenuation in the lower atmosphere is inferior to $0.02 \mathrm{db} / \mathrm{km}$. This limit lies normally at about 16 $\mathrm{Gc} / \mathrm{s}$, but with clouds or strong precipitation it can

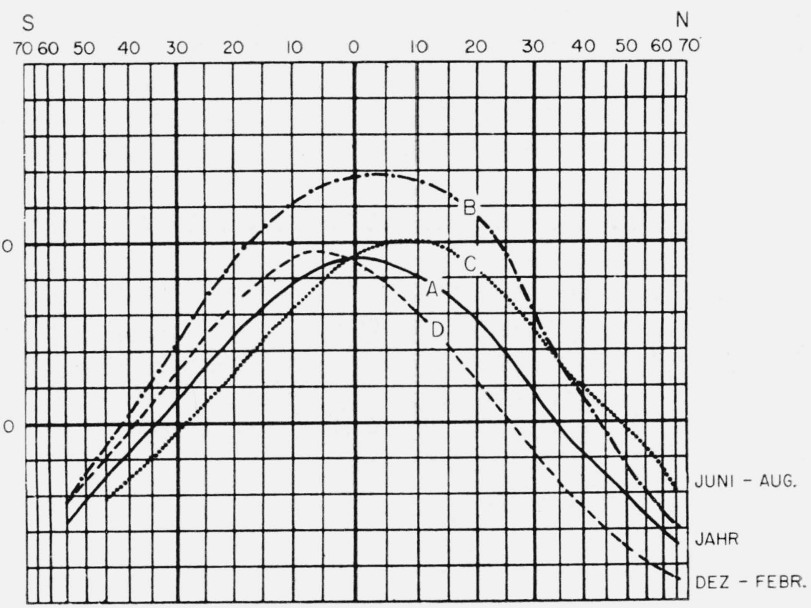

Figure 27. Mean latitude variation of water vapor pressure at the ground for different seasons (full curve: yearly average).

reach lower values, down to $3 \mathrm{Gc} / \mathrm{s}$. Another often more important aspect of tropospheric absorption is discussed in the following section.

\section{Propagation Noise}

With the new amplifiers the internal noise of receivers can be brought down to extremely small values of only a few degree $\mathrm{K}$. Therefore noise sources which have been neglected before must now be considered. In principle propagation noise is produced by any mechanism producing fading. Statistically considered the fading in amplitude and phase can be described by a spectrum; the maximum intensity is mostly found on quite low frequencies, say between 0.01 and $10 \mathrm{c} / \mathrm{s}$. If this spectrum is extended towards higher frequencies it can reach the low frequency band used with the type of communication which is considered. In that part of its spectrum the fading behaves like a stochastic process, one observes noisy signals at the receiver which cannot be distinguished from "true noise."

Propagation noise will mainly be produced by such fading processes for which the center of gravity of spectral intensity lies on relatively high frequencies. Molecular absorption (see sec. 5.2) should be particularly efficient from this point of view as its fluctuations are due to the (thermal) statistical behavior of the molecules so that the main part of the spectrum lies in the communication band itself. In this case the theory of Fraunhofer lines in the solar spectrum may be useful [Unsöld, 1955]. The situation is different for tropospheric and ionospheric turbulence or scintillation, in which case the center of gravity normally lies below the communication band; nevertheless under certain conditions these mechanisms may give an important contribution to the received noise. The problem of propagation noise is a new one, it is typical for earth-space communication and should be studied seriously in the future. 


\section{References}

Aarons, J., W. R. Barron, and J. P. Castelli, Radio astronomy measurements at VHF and microwave, Proc. IRE 46, 325-333 (1958).

Aarons, J., R. S. Roger, J. Thompson, J. Bournazel, E. Vassy, H. A. Hess, K. Rawer, N. Carrara, P. Checeaci, B. Landmark, J. Tröim, B. Hultqvist, L. Liszka, and H. E. Whitney, Atomospheric phenomena noted in simultaneous observations of $1958 \delta 2$ (Sputnik III), Space Science 5, 169-184 (1961)

Aitchison, G. S., and K. Weekes, Some deduction of ionospheric information from the observation of emission from Satellite $1957 \propto 2(\mathrm{I})$, J. Atmospheric and Terrest. Phys. 14, 236-243 (1959a)

Aitchison, G. S., and K. Weekes, Some deduction of ionospheric information from the observation of emission from Satellite $1957 \propto 2$ (II), J. Atmospheric and Terrest. Phys. 14, 244-248 (1959b)

Allan, A. H., and J. E. Drummond, Doppler measurements on soviet satellites, New Zealand J. Sci. Technol. I, 143153 (1958).

Al'pert, Ya. L., F. F. Dobryakova, E. F. Chudesenko, and B. S. Shapiro, On the results of the electron-concentration determinations in the external region of ionosphere made on the basis radio signals from the first Sputnik, Doklady Akad. Nauk. SSSR 120, 743-746 (1958).

Arendt, P. R., On the existence of a strong magnetoionic effect topside of the $F$-maximum of the Kennelly-Heaviside layer, J. Appl. Phys. 30, 793-795 (1959a).

Arendt, P. R., Preliminary results of measurements of Doppler shift of satellite emissions, IRE Trans. AP-, , 99-101 (1959b).

Arendt, P. R., Review of USASRDL satellite propagation studies, IRE Trans. (Mil. El.) 4, 359-360 (1960a).

Arendt, P. R., Frequency scintillation of satellite signals before and after the Argus experiments, IRE Trans. AP-8, No. 1, 73-77 (1960b).

Argence, E., K. Bibl, and K. Rawer, Mesures du nombre de chocs dans les régions E et F2 de l'ionosphere, Mém. soc. roy. sci. Liege 12, 269-280 (1952).

Argence, E., E. Harnischmacher, H. A. Hess, and K. Rawer, Sur le calcul de l'effet Farada relatif à l'ionosphere, Ann. Geophys. 16, 272-275 (1960).

Bain, W. C., and E. Golton, Some effects of the ionosphere on signals from earth satellites, pp. 272-285 of KallmanBijl (ed.), Space Research (1960).

Bauer, S. J., and F. B. Daniels, Ionospheric parameters deduced from the Faraday rotation of lunar radio reflections, J. Geophys. Research 63, 439-442 (1958).

Beckman, R., Radiation effects in quartz - a bibliography, Nucleonics 16, 122 (1958).

Benson, P. F., Effect of line-of-sight aurora on radio star scintillations, J. Geophys. Research 65, 1981-1986 (1960).

Berning, W. W., Earth satellite observations of the ionosphere, Proc. IRE 4\%, 280-288 (1959).

Bernstein, M., G. H. Gougoulis, O. P. Layden, W. T. Scott, and H. D. Tanzman, Satellite Doppler measurements, Proc. IRE 46, 782-783 (1958).

Blackband, W. T., B. Burgess, J. L. Jones, and G. J. Lawson, Deduction of ionospheric electron content from the Faraday fading of signals from artificial earth satellites, Nature 183, 1172-1174 (1959).

Blackband, W. T., The determination of ionospheric electron content by observations of Faraday fading, J. Geophys. Research 65, 1987-1992 (1960). Also pp. 387-396 of Kallman-Bijl (ed.), Space Research (1960).

Blum, E. J., J. F. Denisse, and J. L. Steinberg, Influence de l'ionosphère sur la réception du rayonnement galactique de fréquence $29.5 \mathrm{Mc} / \mathrm{s}$, Compt. Rend. Paris 238, 16951697 (1954).

Booker, H. G., The use of radio stars to study irregular refraction of radio waves in ionosphere, Proc. IRE 46, 298-314 (1958)

Boudouris, G., and J. Bournazel, Mesures sur l'effet DopplerFizeau des satellites artificiels, Onde Electrique 393, 934 (1959).

Boudouris, G., and J. Bournazel, Nouveau principe de mesure de l'absorption ionosphérique, Compt. Rend. Acad. Sci. Paris 250, 4189 (1960).
Boudouris, G., A method for interpreting the Doppler curves of artificial satellites, J. Brit. IRE 20,933 (1960).

Boudouris, G., Etude de l'émission radioélectrique des satellite artificiels, Astronautica Acta 7, Fasc. 2-3, 237 (1961).

Bournazel, J., and E. Vassy, Etude experimentale de l'effet Doppler des satellites artificiels, pp. 492-501 of KallmanBijl (ed.) Space Research (1960)

Bournazel, J., Contribution à l'étude de l'émission radioélectrique des satellites artificiels (Thesis) Paris (1961).

Bowhill, S. A., The Faraday rotation rate of a satellite radiosignal, J. Atmospheric and Terrest. Phys. 13, 175 (1958).

Brenan, P. M., The correlation of radio source scintillation in the southern and northern hemisphere, J. Atmospheric and Terrest. Phys. 19, 287-289 (1960).

Brown, R. R., P. E. Green, Jr., B. Howland, R. M. Lerner R. Manasse, and G. Pettengill, Radio observations of the russian earth satellite, Proc. IRE 45, 1552-1553 (1957).

Browne, J. C., J. E. Evans, and J. K. Hargreaves, Radio echoes from the moon, Proc. Phys. Soc. (London) B69, 901 (1956)

Capon, I. N., The application of ray tracing methods to radio signals from satellites, Proc. Phys. Soc. (London) $7 \%, 337-$ 345 (1960).

Carrara, N., P. F. Checeacci, and L. Ronchi, Determination of the orbit on an artificial satellite, Proc. IRE 47, 75 (1959).

Carrara, N., P. F. Checcacci and L. Ronchi, The determination of the trajectory of artificial satellites, Ricerca Sci. 28, 1341-1355 (1958)

Carru, H., R. Gendrin, and M. Reyssat, Effet Doppler et dérive des fréquences des satellites $1958 \beta 2$ et $1959 \delta$, pp. 502-514 of Kallman-Bijl (ed.) Space Research (1960a).

Carru, H., R. Gendrin, and M. Reyssat, La réfraction ionosphérique pour des fréquences de $20,40,108 \mathrm{MHz}$ et son application à l'effet Doppler des satellites, pp. 286-303 of Kallman-Bijl (ed.), Space Research (1960b).

Cassidy, G. J. A., Radio Doppler measurements on the Russian satellites at the National Standards Laboratory, Proc. IRE (Australia) 19, 105-109 (1958).

Checcacci, P. F., V. Russo, and C. Carrara, Interception of radio signals transmitted by the satellite Sputnik I, Ricerca Sci. 27, 3252-3260 (1957).

Checcacci, P. F., V. Russo, and C. Carrara, Further radio observations on artificial satellites, Ricerca Sci. 28, 18171831 (1958).

Checcacci, P. F., Maintenance and operation of a Doppler data recording station-Part II: Ionospheric Measurements-Final Report Contract AF 61 (052)-182 (Sept. 1960).

Checcacci, P. F., and G. Grassi, Ionospheric observations at Centro Microonde, Firenze, Second Inter. Space Sci. Symposium, Florence, Italy (Apr. 1961).

Dagg, M., The origin of the ionospheric irregularities responsible for radio-star scintillation and spread $F$, J. Atmospheric and Terrest. Phys. 11, 133-150 (1957).

Daniels, F. B., and S. J. Bauer, Faraday fading of earth satellite signals, Nature 182, 599 (1958).

Dewan, E. M., Unusual propagation of satellite signals, Proc. IRE 47, 2020 (1959).

Dimond, H., Interplanetary telemetering, Proc. IRE 48, 679-685 (1960)

Dyce, R. B., Faraday rotation observations of the electron content of the exosphere, J. Geophys. Research 65, 26172618 (1960).

Evans, E. V., The electron content of the ionosphere, J. Atmospheric and Terrest. Phys. 11, 259-271 (1957).

Fejer, J. A., Radio observations of the first Russian artificial earth satellite, Trans. S. African Inst. Elec. Engrs. 48, 363-369 (1957).

Finlay, W. H., Launching IGY satellites, Proc. IRE 46, 357 (1958).

Frihagen, J., and J. Tröim, Scintillation of the $20 \mathrm{MHz}$ signal from the earth satellite $1958 \delta \mathrm{II}, \mathrm{J}$. Atmospheric and Terrest. Phys. 18, 75-78 (1960).

Frihagen, J., and J. Tröim, On the large scale regions of irregularities producing scintillation of signals transmitted from earth satellites, J. Atmospheric and Terrest. Phys. 20, 215-216 (1961a).

Frihagen, J., and J. Tröim, A study of irregularities in the $F$ 
region by means of transmissions from artificial satellites, Final Report Contract AF-61 (052)-344, NDRE Report No. 38 (1961b).

Garriot, O. K., The determination of ionospheric electron content and distribution from satellite observations, J Geophys. Research 65, 1139-1150 and 1151-1157 (1960). Also pp. 371-386 of Kallman-Bijl (ed.) Space Research (1960).

Garriot, O. K., and C. G. Little, The use of geostationary satellites for the study of ionospheric electron content and ionospheric radio wave propagation, J. Geophys. Research 65, 2025-2027 (1960).

Garriot, O. K., and O. G. Villard, Antipodal reception of Sputnik III, Proc. IRE 46, 1950 (1958).

Glazier, E. V. D., E. Rechtin, and J. Voge, Satellites and problems of long range detection and tracking (Agardograph No. 40), (Pergamon Press, London, 1960).

Gruber, S., Statistical analysis of radio star scintillation, J. Atmospheric and Terrest. Phys. 20, 59-71 (1961).

Guier, W. H., and G. C. Weiffenbach, Theoretical analysis of Doppler radio signals from earth satellites, Nature 181, $1525-1526$ (1958).

Hampton, D. E., Analysis of Doppler data from earth satellites, Proc. Inst. Elec. Engrs., London Pt. B 105, 99-100 (1958).

Hann, and R. Süring, Lehrbuch der Meterologie (Leipzig, 1939)

Hess, H. A., Registrierung des Sputnik II auf $40002 \mathrm{kHz}$, NTZ-Nachr. tech. Z. 11, 1-2 (1958).

Hess, H. A., Radio observation during the decay period of the Sovjectic Satellite 58-Delta Two, Geofis. pura e Appl. 45, 62-64 (1960)

Hess, H. A., and K. Rawer, Research and Recording of RFSignals from satellites, AFCRL Report 168 (1960).

Hibberd, F. H., The effect of the ionosphere on the Doppler shift of radio signals from an artificial satellite, J. Atmospheric and Terrest. Phys. 12, 338-340 (1958).

Hibberd, F. H., and J. A. Thomas, The determination of the electron distribution in the upper ionosphere from Satellite Doppler observations, J. Atmospheric and Terrest. Phys. 17, 71-81 (1959)

Hill, R. A., and R. D. Dyce, Some observations of ionospheric Faraday rotation on $106.1 \mathrm{Mc} / \mathrm{s}, \mathrm{J}$. Geophys. Research 65, $173-176(1960)$

Hultqvist, B., and J. Ortner, Strongly absorbing layers below $50 \mathrm{~km}$, Plan. and Space Sci. 1, 193-204 (1959).

Hutchinson, H. P., and P. R. Arendt, Ionospheric scintillations of satellite signals, Proc. IRE 48, 670-671 (1960). Also Xth Intern. Astronaut. Congress London Proc. 1, 402-408 (1959) Publisher, Wein Springer-Verlag, Austria (1960), F. Hecht (ed.).

Kallman, H. K., and Bijl, (ed.), Space Research (COSPARSymposium Nice, 1960) (North Holland Publishing Co., Amsterdam 1960)

Kelso, J. M., The determination of the electron density in inter-planetary space, J. Atmospheric and Terrest. Phys. 16, $357-359$ (1959).

Kelso, J. M., Doppler shifts and Faraday rotation of radio signals in a time-varying, inhomogeneous ionosphere, (I), J. Geophys. Research 65, 3909-3914 (1960). (II), J. Geophys. Research 66, 1107-1115 (1961).

Kent, G. S., High frequency fading observed on the $40 \mathrm{Mc} / \mathrm{s}$ wave radiated from artificial satellite $1957 \alpha$, J. Atmospheric and Terrest. Phys, 16, 10-20 (1959).

Kent, G. S., High frequency fading of the $108 \mathrm{Mc} / \mathrm{s}$ wave radiated from an artificial earth satellite as observed at an equatorial station, J. Atmospheric and Terrest. Phys. 22, 255-269 (1961).

Khaikin, S., Exact determination of the velocity of an artificial satellite, Radio (Moscow) 5-7 (Dec. 1957).

Kitchen, F. A., and R. R. Joy, Some effects of the fine structure of the ionosphere on transmission received from the Russian earth satellite $1958 \delta$, Nature 181, 1759-1761 (1958).

Ko, H. G., Amplitude scintillation of radio star at ultrahigh frequency, Proc. IRE 48, 1871-1880 (1960).

Koster, J. R., and R. W. Wright, Scintillation, spread $F$ and transequatorial scatter, J. Geophys. Research 65, 2303$2306(1960)$.
Kraus, J. D., and J. S. Albus, A note on some signal characteristics of Sputnik I, Proc. IRE 46, 610-611 (1958).

Kraus, J. D., Detection of Sputnik I and II by CW reflection, Proc. IRE 46, 611-612 (1958)

Kraus, J. D., R. C. Higgy, and W. R. Crone. The satellite ionization phenomenon, Proc. IRE 48, 672-678 (1960).

Kraus, J. D., and R. C. Higgy, The relation of the satellite ionization phenomenon to the radiation belts, Proc. IRE 48, 2027-2028 (1960)

Krassovsky, V. I., Exploration of the upper atmosphere with the help of the third Soviet Sputnik, Proc. IRE 47, 289-296 (1959).

Lawrence, R. S., An investigation of perturbations imposed on radio waves penetrating the ionosphere, Proc. IRE 46, 315-320 (1958).

Liszka, L., A type of variation of the signal strength from 1958

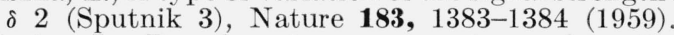

Liszka, L., Doppler phenomenon observed in the Satellite $1958 \delta 2$ transmissions, J. Geophys. Research 66, 15731577 (1961).

Liszka, L., and B. Hultqvist, Investigations of radio transmissions from $1958 \delta 2$ (Sputnik III), made at Kiruna Geophysical Observatory, AFCRL Report 518 (1961).

Little, C. G., and H. Leinbach, Some measurements of high latitude ionospheric absorption using extraterrestrial radio waves, Proc. IRE 46, 334-348 (1958).

Little, C. G., and R. S. Lawrence, The use of polarization fading of satellite signals to study the electron content and irregularities in the ionosphere, J. Research NBS 64D, 335-346 (1960). Also pp. 340-365 of Kallman-Bijl (ed.) Space Research (1960).

Macrakis, M. S., A possible long range communications link between ground and low-orbiting satellites, J. Atmospheric and Terrest. Phys. 19, 260-271 (1960).

Majumdar, R. C., Die Theorie der Ionosphäre, I. Teil, Z. Physik 107, 599-622 (1937).

Mawdsley, J., Fading of satellite transmissions and ionospheric irregularities, J. Atmospheric and Terrest. Phys. 18, 344 (1960).

Mendonca, F., O. Villard, and O. K. Garriot, Some characteristics of the signal received from $1958 \delta 2$, Proc. IRE 48, 2028-2030 (1960).

Millman, G. H., and A. E. Sanders, Radar-lunar investigations at a low geomagnetic latitude, J. Geophys. Research 65, 2619-2626 (1960)

Mitra, A. P., and C. A. Shain, The measurements of ionospheric absorption using absorptions of $18.3 \mathrm{Mc} / \mathrm{s}$ cosmic radio noise, J. Atmospheric and Terrest. Phys. 4, 204-218 (1953)

Miva, K., Y. Taguchi, and S. Tabuchi, Radio observations of the earth satellite $1957 \alpha$, Rept. Ionosphere Research, Japan 12, 16-27 (1958).

Mullard Observatory, Radio observations of the Russian earth satellite, Nature 180, 879-883 (1957).

Munro, G. H., and L. H. Heisler, Recording radio signals from earth satellites, Nature 183, 809-810 (1959).

Murray, W. A. S., and J. K. Hargreaves, Lunar radio echoes and the Faraday effect in the ionosphere, Nature 173, 944 (1954)

Nakata, Y., private communication (1959)

Newton, R. R., Geodetic measurements by analysis of the Doppler frequency received from a satellite, pp. 532-539 of Kallman-Bijl (ed.) Space Research (1960).

Nicolet, M., Collision frequency of electrons in the terrestrial atmosphere, Phys. Fluids 2, 95-99 (1959).

Osborne, J. M., Ranging the satellite by Doppler shift observation, Short Wave Mag. 15, 459-462 (1957).

Parthasarathy, R., R. P. Basler, and R. N. Dewitt, A new method for studying the auroral ionosphere using earth satellites, Proc. IRE 47, 1660 (1959).

Parthasarathy, R., and G. C. Reid, Signal strength recording of the satellite $1958 \delta 2$ at College, Alaska, Proc. IRE 47, 78-79 (1959)

Peterson, A. M., Radio and radar tracking of the Russian earth satellite, Proc. IRE 45, 1553-1554 (1957).

Rawer, K., Radio propagation between a space vehicle and the earth in the presence of the ionosphere, pp. 245-271 of Kallman-Bijl (ed.) Space Research (1960). 
Rawer, K., and K. Suchy, Radio investigation of the ionosphere, Encyclopedia of Physics, 49 (to be published 1962).

Rawer, K., and K. Suchy, Whistlers excited by sound waves, Proc. IRE 49, 968 (1961).

Reid, G. C., and C. Collin, Observations of abnormal VHF radio wave absorption at medium and high latitudes, J. Atmospheric and Terrest. Phys. 14, 63-91 (1959).

Renius, O., and D. Rees, Radiation effects on quartz oscillators, Proc. IRE 48, 1340 (1960).

Roger, R. S., and J. H. Thomson, The Faraday effect in transmissions from fast spinning satellites, Nature 186, $622(1960)$.

Ross, W. J., The determination of ionospheric electron content from satellite Doppler measurements, J. Geophys. Research 65, 2601-2606 and 2606-2615 (1960).

Rush, S., and L. Collin, Effects on radio-astronomical observations due to longitudinal propagation in the presence of field aligned ionization (Letter), Proc. IRE 46, 356-357 1958).

Schmelovsky, K. H., The electron density distribution derived from whistler data and Faraday fading observations, J. Atmospheric and Terrest. Phys. 19, 68-71 (1960).

Schwartzmann, A., and P.D. Stahl, Doppler equation for earth satellite measurements, Proc. IRE 46, 915-916 (1958).

Slee, O. B., Radio scintillations of satellite $1958 a$, Nature 181, 1610 (1958).

Stein, S., O. G. Villard, and K. C. Yeh, Studies of transequatorial ionspheric propagation by the scatter-sounding method, J. Geophys. Research 62, 349-412 (1957).

Strick, H., and J. Mott, Satellite amplitude measurements during solar eclipse of October 2, 1959, AFCRL Report 158 (1961).

Straiton, A. W., and C. W. Talbot, Anomalies in the absorption of radio waves by atmospheric gases, Proc. IRE 48, 898-903 (1960).

Tanzman, H. D., G. A. Macleod, and W. T. Scott, Doppler satellite measurements, Proc. IRE 47, 75-76 (1959).

Thomas, J. A., and F. H. Hibberd, Satellite Doppler measurements and the ionosphere, J. Atmospheric and Terrest. Phys. 13, 376-379 (1958).

Thompson, M. C., Jr., and D. M. Waters, Comparison of phase difference and Doppler shift measurements for studying ionospheric fine structure using earth satellites, Proc. IRE 46, 1960 (1958).
Thomson, J. H., The rotation of the first Russian earth satellite, Phil. Mag. 3, 912-916 (1958).

Tischer, F. J., Propagation Doppler effects in space communication, Proc. IRE 48, 570-574 (1960).

Toman, K., The minimum range equation and the maximum Doppler frequency shift for satellites, Proc. IRE 48, $1339-1340$ (1960).

Unsöld, A., Physik der Sternatmosphären, 2 Aufl. (Berlin $1955)$.

Vassy, E., Etude de l'emission radioélectrique des satellites artificiels, Astronaut. Acta 7, 237-246 (1961).

Vitkevich, V. V., A. D. Kusmin, P. L. Sorochenko, and B. A. Udalzov, Results of radio-astronomical observations of sovjetic cosmical rockets, Iskustvennie Sputniki Semli No. 7 (1961).

Vogelman, J. V., Propagation and communication problems in space, Proc. IRE 48, 567-569 (1960).

Weekes, K., On the interpretation of the Doppler effect from senders in an artificial satellite, J. Atmospheric and Terrest. Phys. 12, 335-338 (1958).

Wells, H. W., Unusual propagation of $40 \mathrm{MHz}$ from the USSR satellite, Proc. IRE 46, 610 (1958).

Whitney, H., H. Strick, J. Aarons, and J. Mott, Sudden amplitude variations of Sputnik III signals, J. Geophys. Research 65, 4210-4212 (1960).

Woyk, E., (E. Chvojkova), The antipodal reception of Sputnik III, Proc. IRE 47, 1144 (1959a).

Woyk, E., (E. Chvojkova), The refraction of radio waves by a spherical ionized layer, J. Atmospheric and Terrest. Phys. 16, 124-135 (1959b).

Wright, J. W., Comment on models of the ionosphere above $h_{\max } F 2$, J. Geophys. Research 65, 2595-2596 (1960).

Yeh, K. C., Second order Faraday rotation formulas, J. Geophys. Research 65, 2548-2550 (1960).

Yeh, K. C., and V. H. Gonzalez, Note on the geometry of the earth magnetic field useful to Faraday effect experiment, J. Geophys. Research 65, 3209-3214 (1960).

Yeh, K. C., and G. W. Swenson, Ionospheric electron content and its variations deduced from satellite observations, J. Geophys. Research 66, 1061-1067 (1961).

(Paper 66D4-202) 